\title{
Representativeness and seasonality of major ion records derived from NEEM firn cores
}

\author{
G. Gfeller ${ }^{1,2}$, H. Fischer ${ }^{1,2}$, M. Bigler ${ }^{1,2}$, S. Schüpbach ${ }^{1,2}$, D. Leuenberger ${ }^{1,2}$, and O. Mini ${ }^{3}$ \\ ${ }^{1}$ University of Bern, Physics Institute, Climate and Environmental Physics, Sidlerstrasse 5, 3012 Bern, Switzerland \\ ${ }^{2}$ Oeschger Centre for Climate Change Research, University of Bern, Zähringerstrasse 25, 3012 Bern, Switzerland \\ ${ }^{3}$ Centre for Ice and Climate, Niels Bohr Institute, University of Copenhagen, Juliane Maries Vej 30, \\ 2100 Copenhagen, Denmark
}

Correspondence to: G. Gfeller (gfeller@climate.unibe.ch)

Received: 1 April 2014 - Published in The Cryosphere Discuss.: 20 May 2014

Revised: 22 August 2014 - Accepted: 11 September 2014 - Published: 16 October 2014

\begin{abstract}
The seasonal and annual representativeness of ionic aerosol proxies (among others, calcium, sodium, ammonium and nitrate) in various firn cores in the vicinity of the NEEM drill site in northwest Greenland have been assessed. Seasonal representativeness is very high as one core explains more than $60 \%$ of the variability within the area. The inter-annual representativeness, however, can be substantially lower (depending on the species) making replicate coring indispensable to derive the atmospheric variability of aerosol species. A single core at the NEEM site records only $30 \%$ of the inter-annual atmospheric variability in some species, while five replicate cores are already needed to cover approximately $70 \%$ of the inter-annual atmospheric variability in all species.

The spatial representativeness is very high within $60 \mathrm{~cm}$, rapidly decorrelates within $10 \mathrm{~m}$ but does not diminish further within $3 \mathrm{~km}$. We attribute this to wind reworking of the snow pack leading to sastrugi formation.

Due to the high resolution and seasonal representativeness of the records we can derive accurate seasonalities of the measured species for modern (AD 1990-2010) times as well as for pre-industrial (AD 1623-1750) times. Sodium and calcium show similar seasonality (peaking in February and March respectively) for modern and pre-industrial times, whereas ammonium and nitrate are influenced by anthropogenic activities. Nitrate and ammonium both peak in May during modern times, whereas during pre-industrial times ammonium peaked during July-August and nitrate during June-July.
\end{abstract}

\section{Introduction}

Ice cores provide a valuable archive for past climate and environmental changes, not only through gases and isotopes, but also through aerosol-derived chemical constituents. Chemistry measurements on ice cores provide information about past climatic conditions for the drilling region as well as for the source regions and give insight into past changes of largescale circulation patterns (e.g. Legrand and Mayewski, 1997; Fischer et al., 2007).

Chemical constituents in ice cores are regarded as representative on inter-annual and seasonal timescales. However, it is well known that they also contain noise introduced by glaciological processes, arising from the movement of surface snow by wind scouring and ablation or atmospheric processes such as unevenly distributed deposition. Removing the noise is essential to acquire climatic signals (with the highest possible temporal resolution), which are representative within a given area (Karlöf et al., 2006). Glaciological noise processes were modelled and quantified for accumulation and $\delta^{18} \mathrm{O}$ by means of standard Fourier spectral methods in the mid-1980s by Fisher et al. (1985). In 2006, Karlöf et al. (2006) used wavelet analysis to decompose signal from noise on Electrical Conductivity Measurements (ECM) and $\delta^{18} \mathrm{O}$ time series from Antarctic firn cores, separated by distances between 3.5 and $7 \mathrm{~km}$, coming to the conclusion that ECM shows a significant common signal if averaged over timescales from 1 to 3 years, whereas $\delta^{18} \mathrm{O}$ showed no statistically significant common signal.

Here we investigate how well monthly and annual averages of Greenland ice core chemistry measurements in the 
region of the NEEM deep ice core drill site reflect a common atmospheric signal on different spatial scales.

To this end chemical constituents and conductivity have been measured on eight cores, drilled close to NEEM camp (Dahl-Jensen et al., 2013) and analysed using the Bern CFA system (Röthlisberger et al., 2000; Kaufmann et al., 2008)) allowing us to resolve monthly variations. The results are compared to other Greenland ice cores drilled close to NEEM camp.

Using the approach of Wigley et al. (1984) (see Sect. 2.6) we are able to give a measure of representativeness of ice core aerosol proxy time series from one single core in terms of atmospheric variations not only on inter-annual and monthly timescales, but also on different spatial scales.

Based on our representativeness study and the collection of firn cores, we are also able to retrieve regional representative information on the seasonal variation in atmospheric concentrations of chemical aerosol traces. The monthly means enable us to assess seasonal variations of chemical constituents which is indispensable to interpret the CFA measurements performed on the NEEM deep ice core and to obtain a precise age-to-depth scale (Kuramoto et al., 2011).

Timing of the seasonality is constrained by assuming different accumulation scenarios. By means of one core which reaches back into pre-industrial times we can also compare modern seasonal variations in chemical constituents with variations from pre-industrial times. The results are compared to seasonality derived from daily snow measurements, air measurements and various snow pits.

\section{Data and methods}

\subsection{Glacio-meteorological characterisation}

The drilling sites of the cores are located in the vicinity of the NEEM camp, Greenland $\left(77^{\circ} 27^{\prime} 0^{\prime \prime} \mathrm{N}, 51^{\circ} 3^{\prime} 36^{\prime \prime} \mathrm{W}\right.$, $2443 \pm 7 \mathrm{~m}$ a.s.1.), see Fig. 1. The mean annual temperature at NEEM is estimated to be $-28.9^{\circ} \mathrm{C}$ according to borehole thermometry, and the present-day annual accumulation rate is estimated to be $0.216 \mathrm{~m}$ of ice equivalent (Buizert et al., 2012).

According to Steen-Larsen et al. (2011), the recent winter minimum in $\delta^{18} \mathrm{O}$ and as such also in temperature at NEEM is encountered during February, whereas the summer maximum of $\delta^{18} \mathrm{O}$ is found in July. Model evaluations of summerwinter accumulation ratio show consistently more accumulation during summer than during winter (Steen-Larsen et al., 2011). Accumulation data from the Greenland Climate Network (GC-Net) Automated Weather Stations (Steffen et al., 1996) at NEEM and Humboldt (closest automated weather station to NEEM) show significant gaps due to power failure but, nevertheless, they point to a more equal summer to winter ratio than in the model. A 10-day back trajectory analysis over the last 30 years shows that most of the air parcels

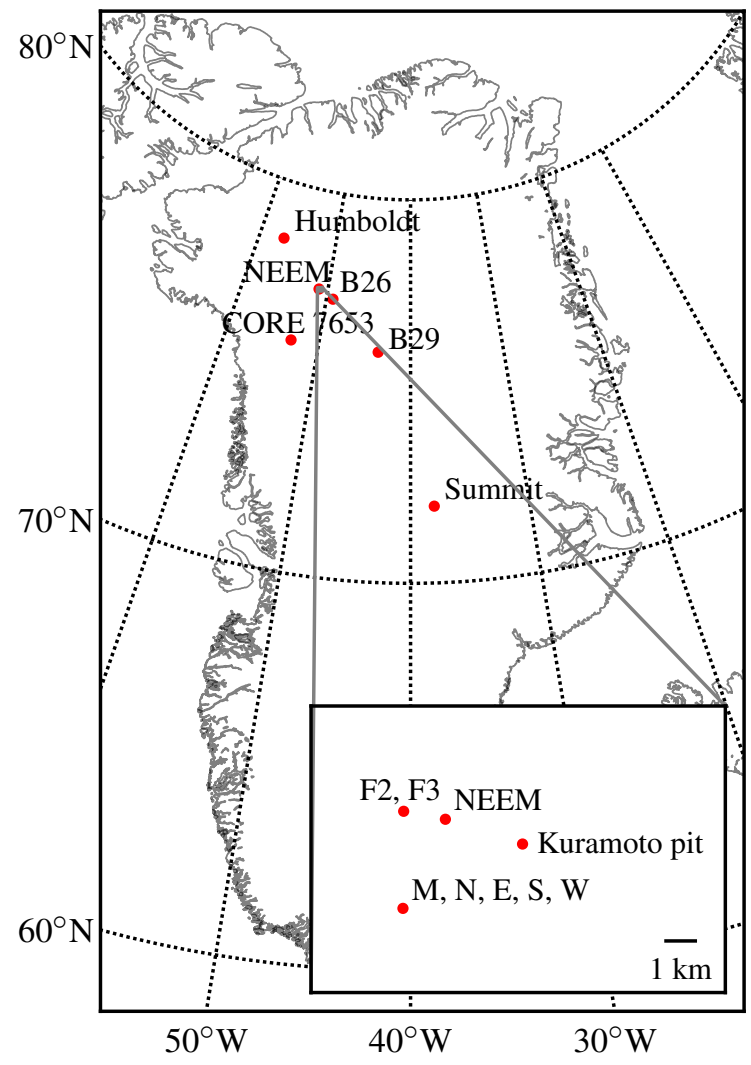

Figure 1. Location map of Greenland with zoom on NEEM camp and proximity.

arriving at NEEM are originating over northern North America and follow the Greenland coast to NEEM. Wind speeds are largest during winter months and smallest during summer months. Both, wind directions and wind speeds, are consistent with the automated weather station measurements.

\subsection{Sampling and measurements}

Five approximately $12 \mathrm{~m}$ long firn cores have been drilled in the vicinity of NEEM camp at $77^{\circ} 25^{\prime} 15^{\prime \prime} \mathrm{N}, 51^{\circ} 5^{\prime} 43^{\prime \prime} \mathrm{W}$, i.e. about $3.5 \mathrm{~km}$ upwind of the NEEM station. Four of the cores have been drilled in a square with $10 \mathrm{~m}$ side length and the fifth in the middle of the square. As this formation looks much like the five on a dice, from now on we will refer to those cores as the dice five cores. According to the geographic directions in which the cores have been drilled, we named them N, E, S, W and M for middle (see Fig. 1). As the top 1-2 $m$ of the firn cores were of bad quality due to the low snow density which prevented CFA measurement from the surface downwards, a $2 \mathrm{~m}$ deep snow pit was sampled at $5 \mathrm{~cm}$ resolution, a few metres south of the five firn cores. The snow pit was sampled mainly for dating purposes and was not used for the representativeness analysis. The snow pit and the firn cores were sampled and drilled between 26 June and 
1 July 2011. For transport from the drilling site to the camp, the ice cores were sealed in plastic bags and stored in ice core boxes. The snow pit samples were stored in pre-cleaned beakers. Between 29 June and 3 July the samples were measured with the Bern CFA-system in the field. The following chemical constituents were analysed continuously: sodium $\left(\mathrm{Na}^{+}\right)$, calcium $\left(\mathrm{Ca}^{2+}\right)$, ammonium $\left(\mathrm{NH}_{4}^{+}\right)$, nitrate $\left(\mathrm{NO}_{3}^{-}\right)$, hydrogen peroxide $\left(\mathrm{H}_{2} \mathrm{O}_{2}\right)$ and hydrogen $\left(\mathrm{H}^{+}\right)$. In addition, the electrolytic conductivity of the sample water was measured continuously.

Three additional firn cores are presented in this work: F2, F3 and NEEM-2008-S1. The firn cores F2 and F3 were both drilled in the same night from 6 to 7 August 2009 and measured continuously with the CFA system during the following days. Cores $\mathrm{F} 2$ and $\mathrm{F} 3$ are about $12 \mathrm{~m}$ long, drilled within $60 \mathrm{~cm}$ of each other in a distance of about $1.5 \mathrm{~km}$ to the west of NEEM camp $\left(77^{\circ} 27^{\prime} 0^{\prime \prime} \mathrm{N}, 51^{\circ} 7^{\prime} 12^{\prime \prime} \mathrm{W}\right)$ and about $3 \mathrm{~km}$ distant from the dice five cores (see Fig. 1). Components measured are the same as for the other cores, except for $\mathrm{Na}^{+}$ in cores F2 and F3, where data were compromised due to measurement failure. Finally the firn core NEEM-2008-S1 refers to the access hole of the NEEM main core, drilled during the 2008 field season. On core NEEM-2008-S1, the same components were analysed as for the dice five cores.

\section{Concentration error estimation and detection limits}

The error in concentration has been estimated by applying a weighted linear (or in the case of $\mathrm{Na}^{+}$non-linear) least square fit to the measured standards. The error of the photomultiplier signal from the fluorescent or absorption measurements is much smaller than the pipetting error of the standard concentrations, which enables us to calculate confidence intervals of the fit. The largest errors arise from mixing the standard concentrations, i.e. by pipetting standards and dispensing water. Pipetting volume measurements resulted in a standard deviation of the volume of about $2 \mu \mathrm{L}$ (for volumes between 100 and $800 \mu \mathrm{L}$ ). The water dispenser has a standard error of $0.1 \mathrm{~mL}$. The errors of the pipetting and dispensing water volume in concentration values $\Delta c$ have been calculated using Gaussian error propagation and applied to the weights $w$ in the fits as $w=\frac{1}{\Delta c}$.

Note that during field seasons it is of high priority to be able to perform measurements fast, therefore one-point calibrations were performed for those species, whose response had been proven previously to be highly linear, such as for $\mathrm{NH}_{4}^{+}$and $\mathrm{H}_{2} \mathrm{O}_{2}$ (Sigg et al., 1994). However, to give an error approximation for those species, an additional extended calibration series has been performed. For the species with more than one-point calibrations, i.e. $\mathrm{Ca}^{2+}, \mathrm{Na}^{+}$and $\mathrm{NO}_{3}^{-}$, the weighted least squares fits have been calculated for all calibration series performed during the NEEM 2011 field season. The mean values of all standard errors are given as measurement errors. The errors over the entire measuring range and
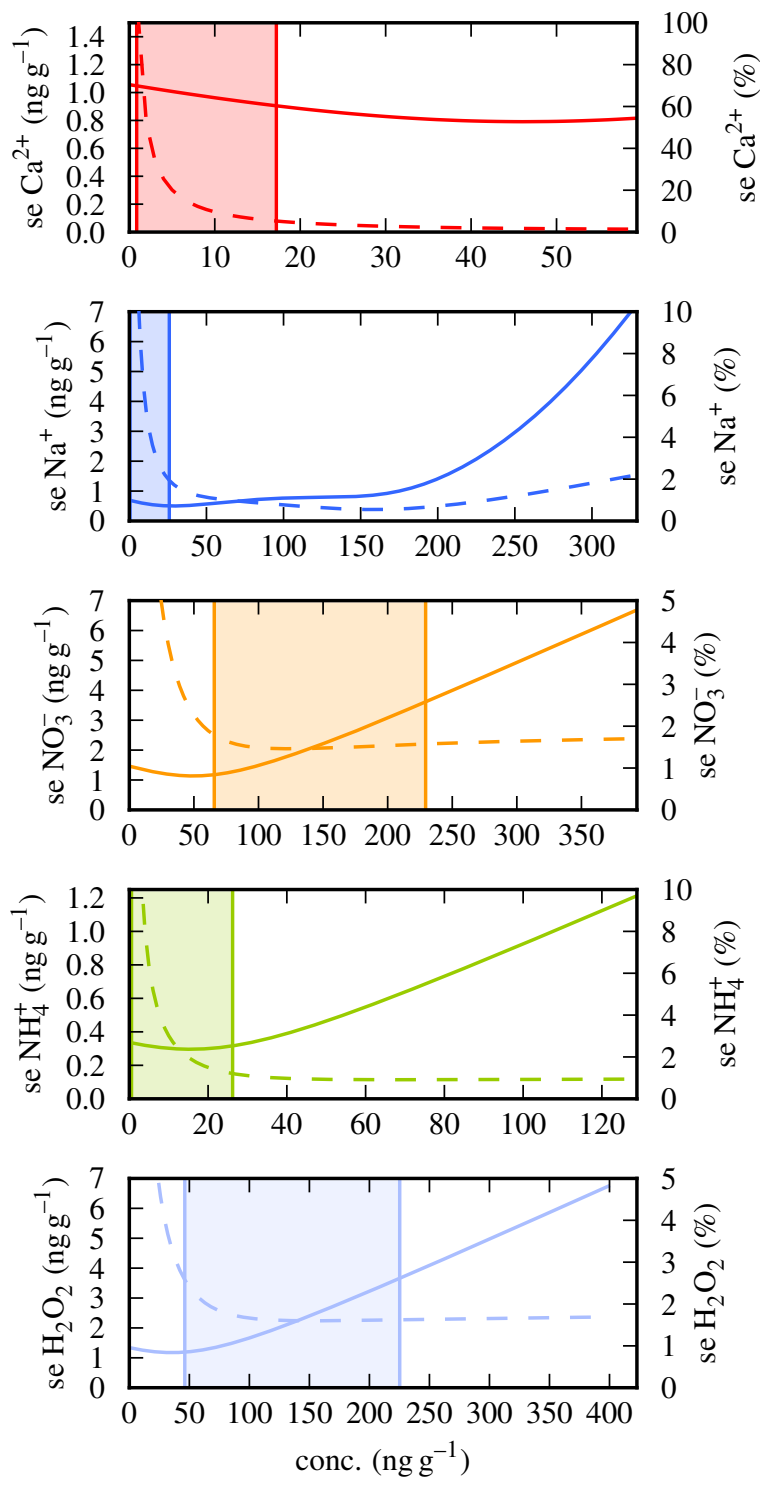

Figure 2. Standard errors (SE) as derived by least square fits of the calibration curves (see text for further details). The errors are shown in absolute values in $\mathrm{ng} \mathrm{g}^{-1}$ (continuous line) and relative to the concentration in percent (dashed line). The $x$-axis represents the measuring range of the firn core data, whereas shaded areas depict the 5 to $95 \%$ inter-quantile ranges as given in Table 1 .

the range 5 to $95 \%$ of the measured firn core concentrations for all species are shown in Fig. 2.

The $\mathrm{H}^{+}$concentrations are only given in arbitrary units as the buffered solutions used to calibrate the electrode have not been run through the system to avoid its contamination. The set-up consists of a small flow-through cell and a pH-electrode as described in Gfeller (2011, Sect. 3.4.2). Due to the very high electrolytic conductivity of $\mathrm{H}^{+}$the measurements are very similar to the conductivity measurements and 
Table 1. The 5 to $95 \%$ inter-quantile range (IQR5) of the firn core data, concentration errors and limits of detection.

\begin{tabular}{lccc}
\hline Component & IQR5 in ng g & Concentration error in $\mathrm{ngg}^{-1}$ & ${\mathrm{LOD} \mathrm{in} \mathrm{ng}^{-1}}^{-1}$ \\
\hline $\mathrm{Ca}^{2+}$ & $0.86-17.2$ & 1.1 & 0.3 \\
$\mathrm{Na}^{+}$ & $0.44-25.9$ & 0.9 & 0.7 \\
$\mathrm{NO}_{3}^{-}$ & $65.8-229.4$ & $1.2-3.5$ & 0.9 \\
$\mathrm{NH}_{4}^{+}$ & $0.56-26.2$ & 0.4 & 0.1 \\
$\mathrm{H}_{2} \mathrm{O}_{2}$ & $46.2-225.2$ & $1.2-4$ & 1.2 \\
\hline
\end{tabular}

are therefore not shown here. The limits of detection (LOD) of all species have been calculated as three times the standard deviation of ultrapure water (i.e. blank) measurements and are shown in Table 1.

As illustrated in Fig. 2, the relative concentration error is concentration dependent and can in some cases be as high as $100 \%$. For the majority of the samples, however, the relative concentration error is smaller than $10 \%$ (30\% in the case of $\mathrm{Ca}^{2+}$ ) as also estimated by triplicate measurements, performed previously by Röthlisberger et al. (2000).

Melting of the firn was performed at an average speed of $6 \mathrm{~cm}$ per minute. The time required for the response of a step function change in concentration to rise from 10 to $90 \%$ of its final value, was smaller than $30 \mathrm{~s}$ in all parameters, resulting in a depth resolution better than $3 \mathrm{~cm}$ of firn or better than $1.5 \mathrm{~cm}$ in water equivalent. In the uppermost parts of the firn, the resolution might be slightly lower due to a small wicking effect, which causes the sample water to be sucked up into the porous firn.

\subsection{Depth scale, dating and accumulation rate}

All dice five cores have been dated by counting annual layers in our multi-component data set. In addition, the four outer cores have been matched to the centre core by assigning tie points to characteristic peaks found in all cores. Peak characteristics are provided mostly by $\mathrm{H}_{2} \mathrm{O}_{2}$, which shows a very distinctive winter to summer ratio, and $\mathrm{NH}_{4}^{+}$showing some high peaks in all cores. Small gaps in the data because of breaks in the cores or air bubbles in the detector cells have been interpolated. By using a simple algorithm, the tie points have then been moved within a small range to achieve maximum signal correlation between all cores. This step is necessary to synchronise the cores in a more objective way.

Since the firn pit and the cores are overlapping, it is possible to perform annual layer counting from the very top of the cores. Using $\mathrm{H}_{2} \mathrm{O}_{2}$ as a metronome (assuming minima in January and maxima in July) a half annual age-todepth scale has been established for all cores. The $\mathrm{H}_{2} \mathrm{O}_{2}$ seasonality is supported by several ice cores drilled within the Program for Arctic Regional Climate Assessment (PARCA) project in 1997 (Mosley-Thompson et al., 2001). In that study, $\delta^{18} \mathrm{O}$ and $\mathrm{H}_{2} \mathrm{O}_{2}$ were measured and the timing of the winter minima analysed. Those measurements (especially core 7653 , closest to NEEM, although very short) point to the fact that $\mathrm{H}_{2} \mathrm{O}_{2}$ winter minima lead $\delta^{18} \mathrm{O}$ by about 1 month. With the $\delta^{18} \mathrm{O}$ seasonality determined for NEEM by SteenLarsen et al. (2011), this implies a $\mathrm{H}_{2} \mathrm{O}_{2}$ minimum in January and a maximum in July. This is also supported by MosleyThompson et al. (2001) who state that the $\mathrm{H}_{2} \mathrm{O}_{2}$ minimum is in January, whereas $\mathrm{H}_{2} \mathrm{O}_{2}$ maxima are more variable.

Density measurements have not been performed on our cores. In order to get an estimate of the density and thus be able to calculate water equivalent depth scales and accumulation rates, two different density profiles have been used. First, an empirical fit to the density profile of the NEEM main core by Buizert et al. (2012) has been used and second, a Herron-Langway model (Herron and Langway, 1980) applied to density measurements of the NEEM07S3 core, drilled in the vicinity of NEEM camp (Steen-Larsen et al., 2011). As parameters for the Herron-Langway model we used a mean temperature of $-28.9^{\circ} \mathrm{C}$, an annual accumulation rate of $0.2 \mathrm{~m}$ water equivalent, a surface snow density of $0.34 \mathrm{~g} \mathrm{~cm}^{-3}$ and an ice density of $0.92 \mathrm{~g} \mathrm{~cm}^{-3}$.

To refine the age scale to a sub-annual scale, two different accumulation scenarios were taken into consideration. One scenario, where the accumulation rate does not vary throughout the year (i.e. a linear age-depth relationship is assumed) and another, where the accumulation rate during winter is half the summer accumulation. The first scenario is supported by the scarce weather station measurements, whereas the second scenario is supported by several models shown in Steen-Larsen et al. (2011).

The dice five cores cover roughly 20 years over $12 \mathrm{~m}$ (roughly $5 \mathrm{~cm}$ per month) with a depth resolution of $3 \mathrm{~cm}$ or better. This is sufficient to calculate monthly means without oversampling. The same holds for cores F2 and F3, which also cover roughly 20 years.

The NEEM-2008-S1 core has been dated using the $\mathrm{Na}^{+}$ peak as time marker. The same technique, as for the five other firn cores, to refine the age scale has been applied. Core NEEM-2008-S1 covers a time period of 373 years from 1623-1996. 


\subsection{Seasonality}

The depth-to-age relationship enables us to calculate the average seasonality for each species. The monthly average concentration $\bar{X}_{k}$ in the study area is given by

$\bar{X}_{k}=\frac{1}{N} \sum_{j=1}^{N} \frac{1}{n_{\mathrm{a}}} \sum_{i=1}^{n_{\mathrm{a}}} X_{i, j, k}$,

where $N$ stands for the number of cores, $n_{\mathrm{a}}$ for the number of years and $k$ for the months. $X_{i, j, k}$ represents a regrouping of the signal of each core in years and months. Note that monthly concentration $X_{i, j, k}$ is dependent on the age scale and, thus, on the assumed seasonal variation in accumulation. Accordingly, average seasonality have been calculated for our two accumulation scenarios.

The mean seasonality has also been calculated for the time series derived only from the NEEM-2008-S1 core which covers the pre-industrial time period of AD 1623-1750.

\subsection{Distribution of mean annual data}

In absence of any long-term trends, the annual mean data of the dice five cores follow in first order a log-normal distribution. However, as our time series are too short to show a representative histogram, we use the data of NEEM-2008$\mathrm{S} 1$ arguing that its distributions are the same as those of the dice five cores, with the exception of the species showing anthropogenic trends which we treated separately. In Fig. 3 the distribution of the logarithmised data of core NEEM-2008$\mathrm{S} 1$ since 1750 is shown. To take into account the anthropogenic increase, a locally weighted scatter-plot smoothing filter (LOWESS) (Cleveland, 1979) with parameter $f=0.15$ has been applied to $\mathrm{NO}_{3}^{-}$and conductivity and subtracted from the original data. $\chi^{2}$-tests showed that at the 0.95 confidence level the hypothesis that the (trend corrected) data are not normally distributed can not be rejected for any of the species except for conductivity. This essentially tells us that the data can be considered to be log-normally distributed as a first approximation.

\subsection{Representativeness estimate}

All the species measured in the cores are subject to nonatmospheric processes (further referred to as noise) arising from secondary effects such as wind scouring, re-evaporation as well as the event-like character of wet aerosol deposition by individual precipitation events. In the following, it is assumed that the measured time series in an ice core $i X_{i}(t)$ consists of a common deterministic signal $\mu(t)$ and some additional individual noise $\xi_{i}(t)$ with variance $\sigma_{\xi}^{2}(t)$ :

$X_{i}(t)=\mu(t)+\xi_{i}(t)$

where $t$ stands for either the months, if we are looking at the monthly resolved data set, or the years, if we only consider

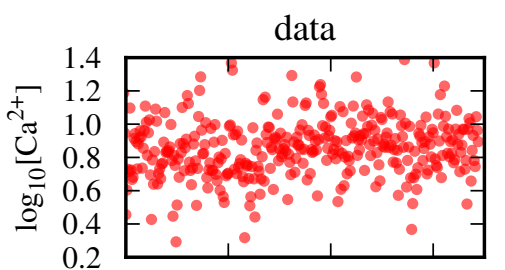

normalised

histograms
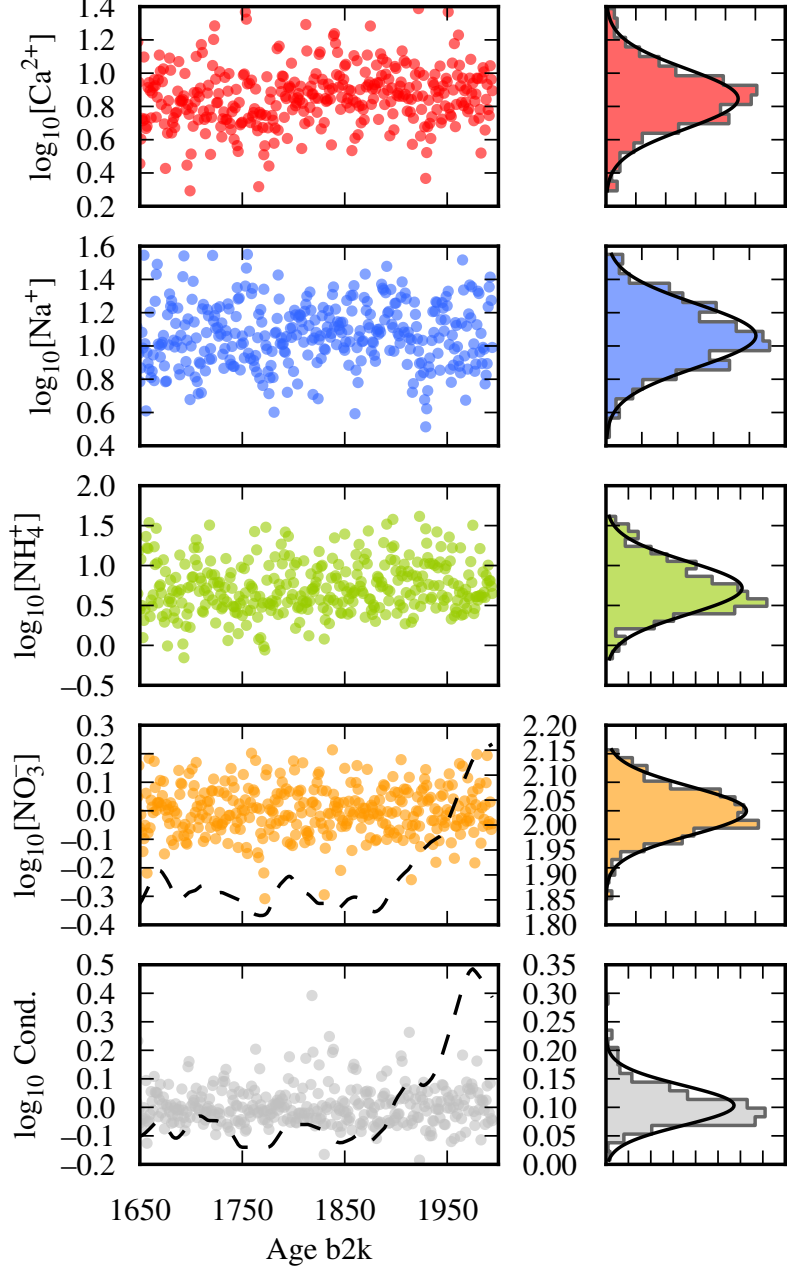

0.35

0.30

0.25

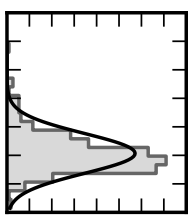

Figure 3. Histograms for annual logarithmised data from the NEEM-2008-S1 core since 1650. Anthropogenic trends (dashed lines with $y$-axis on the right side) in conductivity and $\mathrm{NO}_{3}^{-}$have been removed using a LOWESS filter with parameter $f=0.15$. The logarithmised data of all species, except conductivity, follow to first order a normal distribution (see text). Normalised histograms share the same $y$-axis as the annual logarithmised data.

annual averages. It is crucial to discuss monthly and annually resolved data separately, since the method we are going to use to calculate the representativeness includes Pearson correlations whose coefficients are much higher for the monthly resolved data set since the high-resolution time series are autocorrelated due to their seasonality.

If the variance $\sigma_{\xi}^{2}(t)$ is the same in all cores and time, the best estimate of $\mu(t)$ is $\bar{X}(t)=\frac{1}{N} \sum_{i=1}^{N} X_{i}(t)$.

For most of the measured species, the noise depends on the signal (see Fig. 4), which practically forbids us to use the previous definitions. However, as shown in Sect. 2.5, most of our data follow to first order a log-normal distribution. 

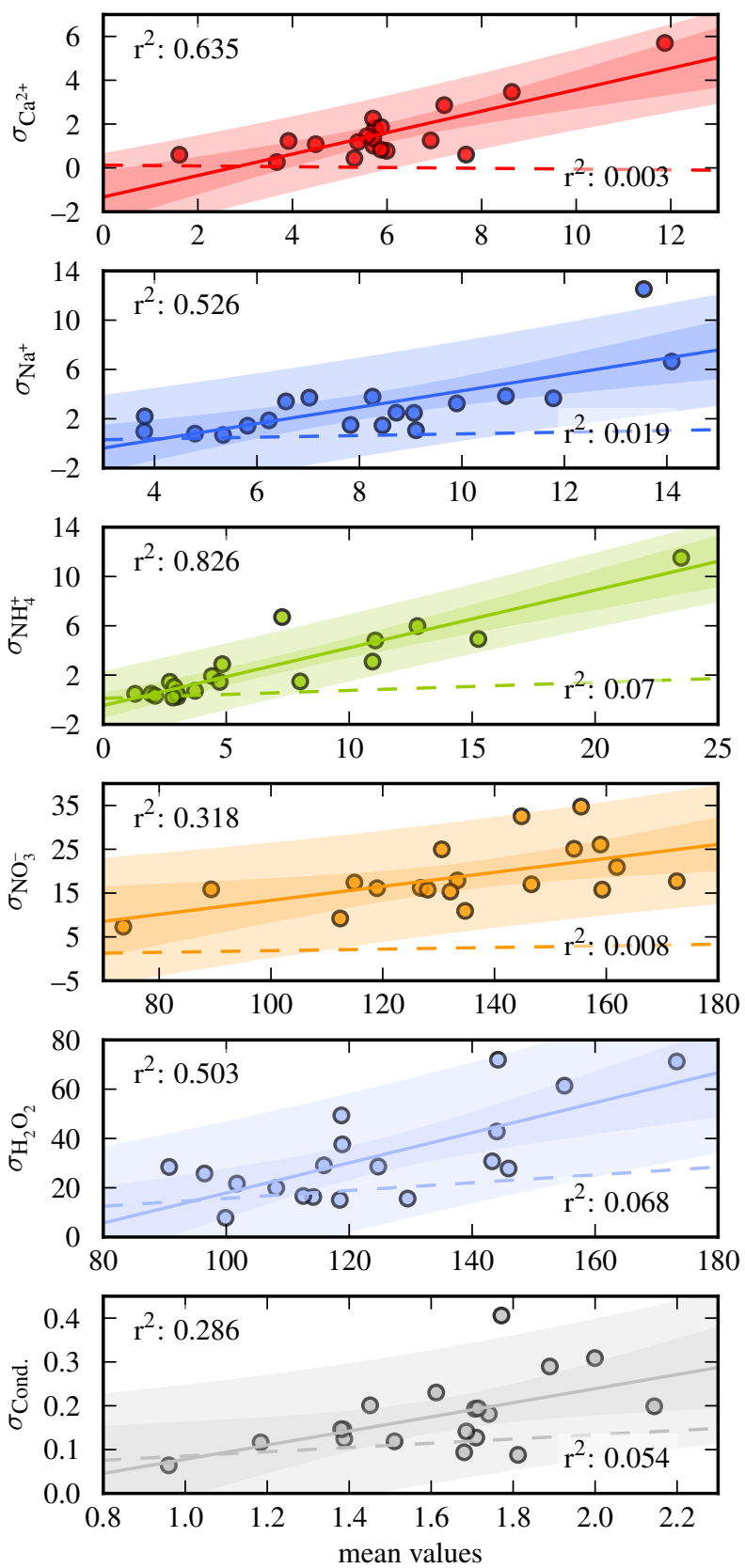

Figure 4. Between-series standard deviations $(\sigma)$ for each year plotted against the between-series mean. Full lines depict the fit of the measured concentration data (in $\mu \mathrm{S} \mathrm{cm}^{-1}$ for conductivity and in $\mathrm{ng} \mathrm{g}^{-1}$ for all other species), whereas dashed lines depict the fit of the logarithmised data. Coefficient of determination are given in the upper left corner and lower right corner for normal data and logarithmised data respectively. Dark shaded areas show the $95 \%$ confidence intervals for the normal data fit whereas light shaded areas show the $95 \%$ prediction intervals for a linear regression of the measured concentration data. Confidence and prediction intervals are not shown for logarithmised data.
Table 2. Parameters for two-way analysis of variance (ANOVA).

\begin{tabular}{ll}
\hline Within-series sum of squares & $\mathrm{SSY}=N \sum_{t=1}^{T}(\bar{X}(t)-\bar{X})^{2}$ \\
Between-series sum of squares & $\mathrm{SSC}=T \sum_{i=1}^{N}\left(\bar{X}_{i}-\bar{X}\right)^{2}$ \\
Total sum of squares & $\mathrm{SST}=\sum_{i=1}^{N} \sum_{t=1}^{T}\left(X_{i}(t)-\bar{X}\right)^{2}$ \\
Error sum of squares & $\mathrm{SSE}=\mathrm{SST}-\mathrm{SSY}-\mathrm{SSC}$ \\
\hline
\end{tabular}

Taking the logarithm of the data not only makes the data of each core normally distributed (see Fig. 3), but also removes the noise dependency on the signal. From now on we will therefore only use the logarithmised data which we will refer to as $Y_{i}(t)=\log _{10} X_{i}(t)$.

To answer the question of how good $\bar{Y}(t)$ represents the deterministic signal $\mu(t)$, we follow the methodology of Wigley et al. (1984) briefly summarised in the following.

We define representativeness as the square of the average of the inter-series correlation $R_{n, N}$, which itself is defined as the Pearson correlation coefficient between two time series, the average of a $n$-subset of $N$ cores $\bar{Y}_{t, n}$ and the average of all $N$ cores $\bar{Y}_{t, N}$ (Wigley et al., 1984):

$R_{n, N}=\frac{\frac{1}{T-1} \sum_{t=1}^{T}\left(\bar{Y}_{t, n}-\overline{\bar{Y}}_{n}\right)\left(\bar{Y}_{t, N}-\overline{\bar{Y}}_{N}\right)}{s_{n} s_{N}}$,

where $n$ goes from 1 to $N$, the $T$ depicts the length of the time series and $s_{n}$ and $s_{N}$ stand for the unbiased standard deviation of the average of the $n$-subset and the average of the whole set $N$, respectively. The average value of $R_{n, N}$ for all subsets of size $n\left(\bar{R}_{n, N}\right)$ is a measure of the accuracy of a $n$-subset average as an estimate of the whole set average. The $\bar{R}_{n, N}^{2}$ is then the representativeness of the mean of all subsets with size $n$. To find out how representative one or several cores are for the given area we let $N$ go to infinity representing a fictive infinite amount of cores drilled in the given area, corresponding to the mean atmospheric signal. To do this we need to find an expression of $\bar{R}_{n, N}^{2}$ depending only on the variables $n$ and $N$.

Wigley et al. (1984) showed that such an expression is given by $\tilde{R}_{n, N}^{2}$ where the tilde depicts an approximation of $\bar{R}_{n, N}^{2}$ :

$\tilde{R}_{n, N}^{2}=\frac{n[1+(N-1) \hat{a}]}{N[1+(n-1) \hat{a}]} \approx \bar{R}_{n, N}^{2}$,

where $\hat{a}$ depicts the unbiased fractional variance

$\hat{a}=\frac{\mathrm{SSY}-\frac{\mathrm{SSE}}{N-1}}{\mathrm{SSY}+\mathrm{SSE}}$

and SSE and SSY are terms used in the two-way analysis of variance (ANOVA) given in Table 2. 

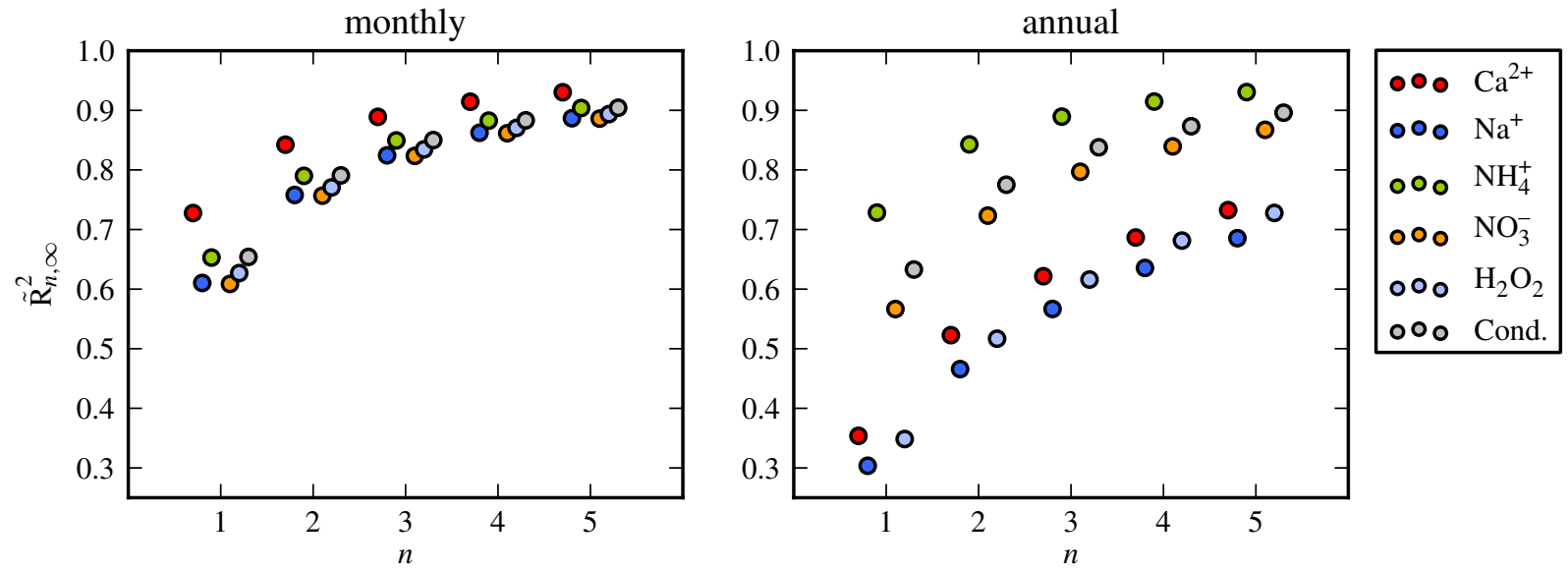

Figure 5. Monthly and annual representativeness of the different species of the dice five firn cores depending on the number of cores $n$.

To see how well one or several cores of our data set represent the time series population mean $\mu(t)$, we use Eq. (3) and let $N$ go to infinity, which gives us

$\tilde{R}_{n, \infty}^{2}=\frac{n \hat{a}}{1+(n-1) \hat{a}}$

as a measurement of the representativeness on a subset of $n$ cores for the entire region. The $\tilde{R}_{n, \infty}^{2}$ have been calculated for the monthly as well as the annual time series for subsets with size 1 to 5 . To estimate the influence of the accumulation rate, $\tilde{R}_{n, N}^{2}$ was also computed for the annual fluxes, i.e. the concentration multiplied by the accumulation rate: $F_{i}(t, A)=X_{i}(t) A_{i}(t)$, where $A_{i}(t)$ depicts the annual accumulation of core $i$. The representativeness of a single core and of all five cores (monthly and annual resolution) are listed in Table 5. An overview of $\tilde{R}_{n, \infty}^{2}$ for $n=1, \ldots, 5$ is given in Fig. 5. Note the much higher representativeness of the monthly time series arising from the autocorrelation induced by the seasonality.

To get rid of the autocorrelation but still be able to use the monthly resolution we divide the time series into single months $X_{i, t_{k}}$, where $k$ stands for an individual month, i.e we only look at all Januaries, Februaries etc. From now on we will refer to this kind of representativeness as "single month representativeness".

To be able to give an error estimate for the annual and the single month representativeness we performed a bootstrapping analysis: $n_{\mathrm{a}}$ (length of $t_{k}$, i.e. number of years) values are drawn 10000 times from the original data set (e.g. all February values from the first core: $X_{1, t_{2}}$ ) with repetitions, i.e. it is possible to draw the same value multiple times. This procedure has been performed for all cores, generating new data sets from the original ones. For each new data set, the representativeness has been calculated following the Wigley method described above. In Fig. 6 the mean representativeness and the $95 \%$ confidence intervals of the bootstrapped data are shown.

\subsection{Relationship between distance and representativeness}

In the previous chapter we only quantified the representativeness within the dice five formation, here we want to look at representativeness on different spatial scales. Since we have two other cores, i.e. cores F2 and F3, which have been drilled within $60 \mathrm{~cm}$ of each other, but about $3 \mathrm{~km}$ away from the five other cores, it is possible to estimate representativeness of the cores on a smaller spatial scale as well as on a larger one. To get an estimate of how the representativeness changes with distance, $\tilde{R}_{1, \infty}^{2}$ has been calculated and averaged for all subsets of two cores, which have approximately the same distance to each other, i.e. cores F2 and F3 in short range $(60 \mathrm{~cm})$, cores $\mathrm{M}, \mathrm{N}, \mathrm{E}, \mathrm{S}, \mathrm{W}$ in medium range (roughly $10 \mathrm{~m})$ and F2, F3 with $\mathrm{M}, \mathrm{N}, \mathrm{E}, \mathrm{S}, \mathrm{W}$ in large distance $(3 \mathrm{~km})$. Due to missing data in core F3 the data set is reduced to only 12 years.

In a dice five, there are three different distances between the cores, diagonal, side distance and distance to the centre. As an attempt to get information about representativeness and distance on such a short range, $\tilde{R}_{1, \infty}^{2}$ values have been calculated for each of those distances as well.

\section{Results}

\subsection{High-resolution firn core records}

The dice five cores show similar signals in all components (see Fig. 7). Mean values and annual variability are shown in Table 3. The $\mathrm{Ca}^{2+}, \mathrm{Na}^{+}$and $\mathrm{NH}_{4}^{+}$show low concentrations around $6 \mathrm{ng} \mathrm{g}^{-1}$ whereas $\mathrm{NO}_{3}^{-}$and $\mathrm{H}_{2} \mathrm{O}_{2}$ show higher concentrations around $130 \mathrm{ng} \mathrm{g}^{-1}$. For $\mathrm{Ca}^{2+}, \mathrm{Na}^{+}$and $\mathrm{NH}_{4}^{+}$, the annual variability is around the same as the annual mean values, whereas for $\mathrm{NO}_{3}^{-}$and $\mathrm{H}_{2} \mathrm{O}_{2}$ it is relatively lower, around $40 \mathrm{ng} \mathrm{g}^{-1}$. Core $\mathrm{M}$ exhibits a large variability in $\mathrm{Na}^{+}$ 

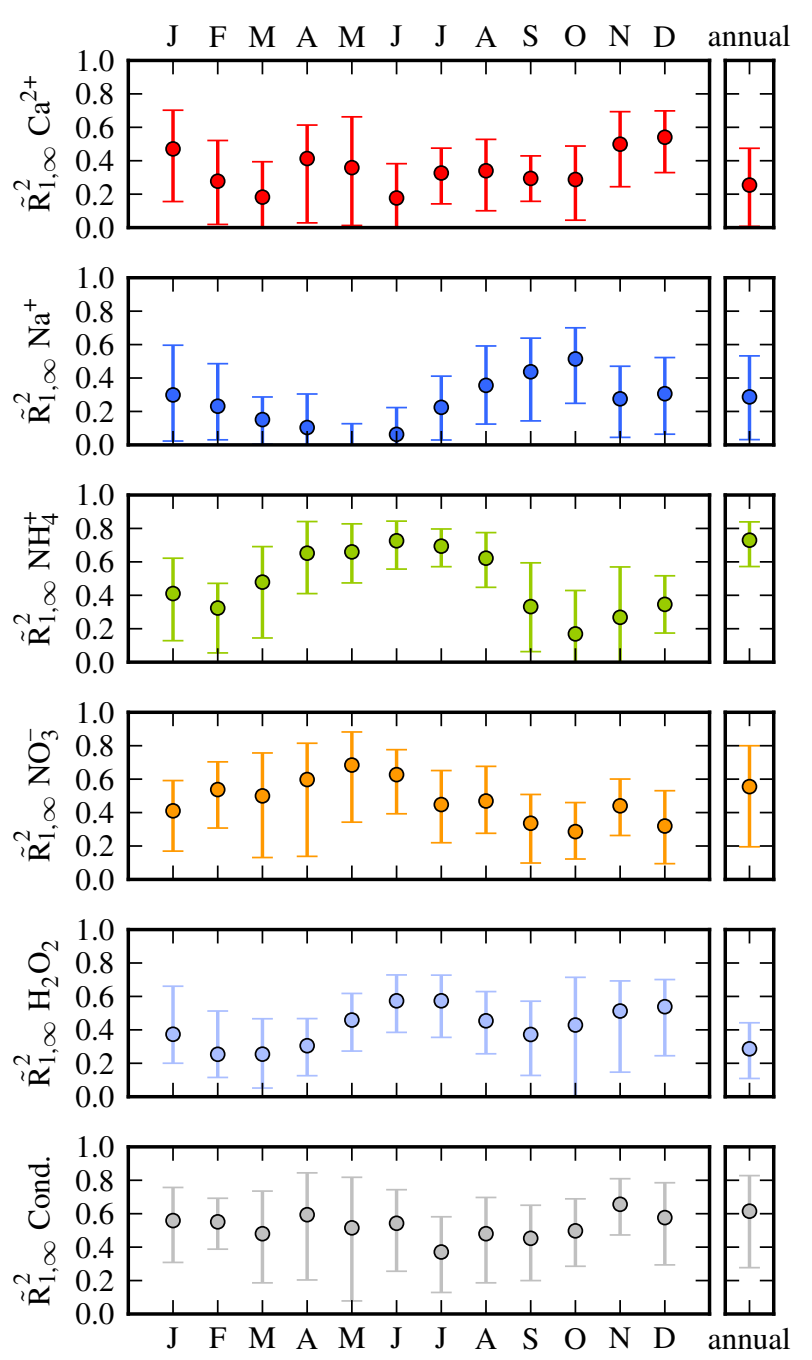

Figure 6. Average of bootstrapped representativeness values as derived from the dice five firn core (coloured full circles). Error bars depict $95 \%$ bootstrapped confidence intervals. The left plot shows the single month representativeness, whereas the right plot shows the representativeness of inter-annual variations.

(roughly twice the variability of the other cores) due to a very high peak in 1994. The cores F2, F3 and NEEM-2008-S1 show overall a little bit higher concentrations than the dice five cores but agree very well in timing.

Here, the cores and the snow pit presented in this work are compared to other data available in the literature, i.e. an approximately $2 \mathrm{~m}$ deep snow pit dug in 2009 (2.6 km East from NEEM camp) by Kuramoto et al. (2011), Ion Chromatography (IC) measurements of firn core B26 (Hausbrand, 1998) and CFA measurements on core B29 (Sommer, 1996), both cores drilled during the North Greenland Traverse (B26 about $50 \mathrm{~km}$ southeast from NEEM camp, B29 further southeast, about $250 \mathrm{~km}$ from NEEM camp). Contrary to the cores presented in this work, B26 and B29 have not been measured in the field, but transported and stored for some time before being measured in the laboratory. On core $\mathrm{B} 26, \mathrm{Ca}^{2+}, \mathrm{Na}^{+}$, $\mathrm{NH}_{4}^{+}$and $\mathrm{NO}_{3}^{-}$have been measured, whereas $\mathrm{B} 29$ comprises only $\mathrm{Ca}^{2+}, \mathrm{NH}_{4}^{+}$and $\mathrm{H}_{2} \mathrm{O}_{2}$ measurements. The snowpit of Kuramoto et al. (2011) covers $\mathrm{Ca}^{2+}, \mathrm{Na}^{+}$and $\mathrm{NO}_{3}^{-}$. IC measurements on core B26 yield yearly resolution, whereas the other data show monthly or better resolved data. All the data are shown in Fig. 7.

The measurements of Kuramoto et al. (2011) agree very well with our data, both in concentration and in timing. Core B26 agrees well in $\mathrm{Ca}^{2+}, \mathrm{Na}^{+}$and $\mathrm{NO}_{3}^{-}$but less in $\mathrm{NH}_{4}^{+}$, whose concentration is considerably higher in B26 than in the cores presented in this work. The high $\mathrm{NH}_{4}^{+}$values measured by IC are mainly due to the rather large error arising from the measurement itself, where liquid samples in the laboratory are exposed to elevated levels of gaseous $\mathrm{NH}_{3}$ (Fischer, 1997; Hausbrand, 1998). Core B29 shows higher concentrations in $\mathrm{Ca}^{2+}$ than our new cores which might be due to the fact that the porous firn core has not been measured in the field, and thus may be subject to contamination during transportation or storage. $\mathrm{Na}^{+}$, however, agrees well with our data. Other than the mentioned discrepancies the annual means agree within the error bars, as shown in Table 3.

Also the annual accumulation values have been derived from the dated ice cores after correction for densification. On average the mean annual accumulation is about $0.25 \mathrm{~m} \mathrm{w}$. eq. in our firn cores independent of the density profile used (see Table 4). Kuramoto et al. (2011) calculated a mean accumulation rate of $0.176 \mathrm{~m} \mathrm{w}$. eq. for their $2 \mathrm{~m}$ snow pit, which is substantially less than what we calculated (see Fig. 7) - however, not statistically significant, as their measurements only cover three years. Steen-Larsen et al. (2011) calculated accumulation rates from core NEEM07S3 and derived a value of $0.22 \mathrm{~m}$ i. eq., which corresponds to about $0.2 \mathrm{mw}$. eq. Similarly, Buizert et al. (2012) gives a value of $0.227 \mathrm{mi}$. eq. $\mathrm{a}^{-1}$, i.e. $0.209 \mathrm{~m}$ w. eq. $\mathrm{a}^{-1}$. This value is about $20 \%$ lower than the dice five cores and may point to significant small-scale variability in snow deposition for example induced by dune formation within a few kilometres. As shown in a study of West Central Greenland by Dunse et al. (2008), accumulation in this area is representative only over several hundred metres with variation of about $15 \%$ around the spatial mean.

\subsection{Representativeness of the dice five cores}

The representativeness values of one core and of five cores of each chemical species in monthly and annual resolution are listed in Table 5. In addition, the representativeness of the annual flux is shown. The representativeness values of the monthly resolved data are much higher than those of the annual mean data since the monthly resolution includes the autocorrelation of the seasonality in each species.

Including the seasonal variation in the aerosol chemistry data, one core is able to explain more than $60 \%$ of the total variance in each measured species whereas five cores even 


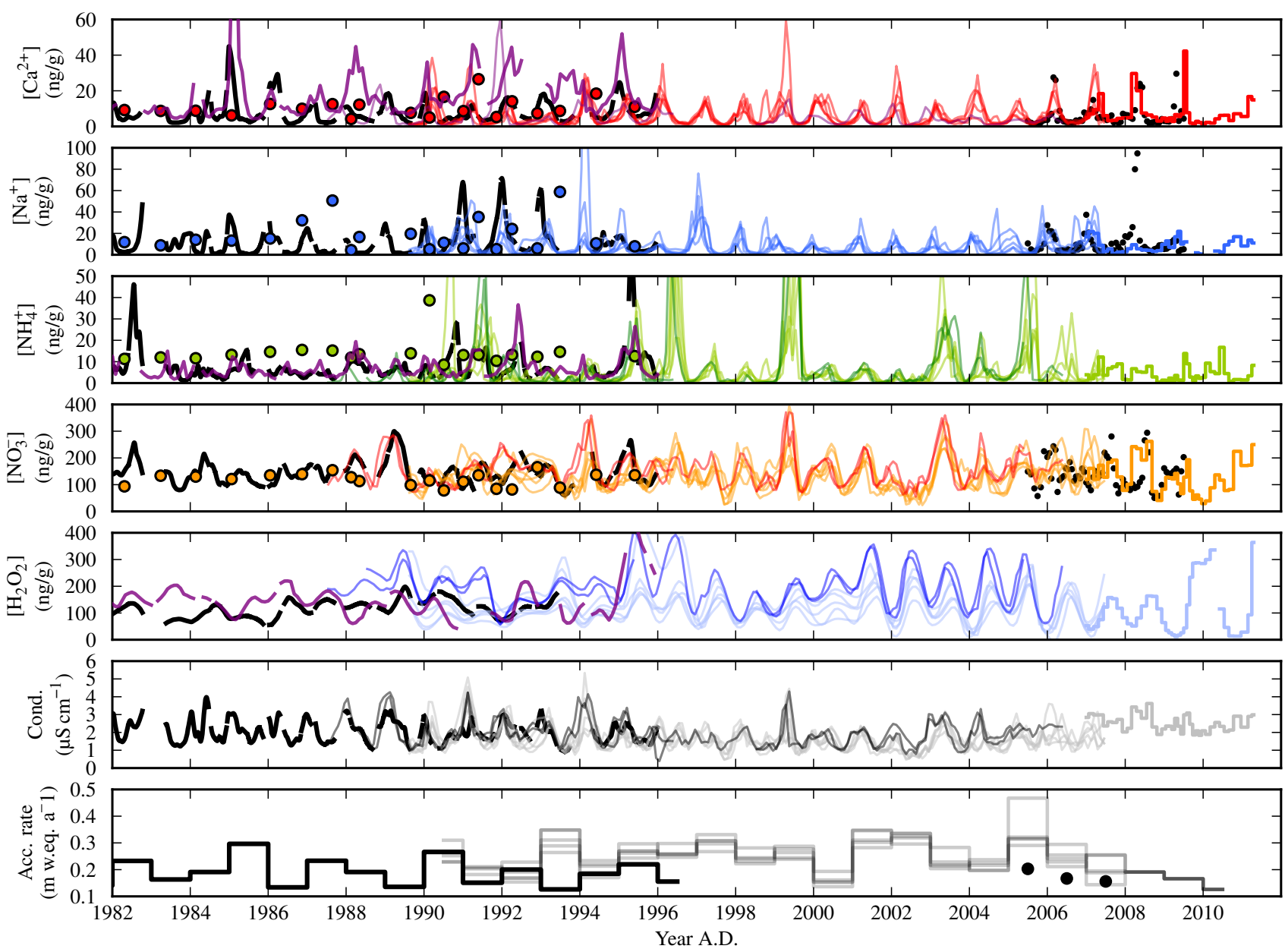

Figure 7. Coloured lines: dice five firn cores (this work); dark coloured lines: cores F2 and F3 (in $\mathrm{Ca}^{2+}$ only core F3 is shown); coloured dots: core B26; black dots: Kuramoto pit; black line: core S1. Purple lines in $\mathrm{Ca}^{2+}, \mathrm{NH}_{4}^{+}$and $\mathrm{H}_{2} \mathrm{O}_{2}$ : B29.

Table 3. Annual mean concentrations and standard deviations (both in $\mathrm{ng} \mathrm{g}^{-1}$, with the exception of conductivity where means and standard deviations are given in $\mu \mathrm{S} \mathrm{cm}^{-1}$ ) over the intervals shown in Fig. 7.

\begin{tabular}{lllllll}
\hline Species & $\mathrm{M}$ & $\mathrm{N}$ & $\mathrm{E}$ & $\mathrm{S}$ & $\mathrm{W}$ & \\
\hline $\mathrm{Ca}^{2+}$ & $4.7 \pm 4.7$ & $6.9 \pm 5.2$ & $5.7 \pm 4.4$ & $5.8 \pm 5.7$ & $6.3 \pm 5.6$ & \\
$\mathrm{Na}^{+}$ & $9.7 \pm 14.1$ & $9.5 \pm 7.6$ & $6.9 \pm 6.0$ & $6.1 \pm 5.7$ & $8.1 \pm 8.7$ & \\
$\mathrm{NH}_{4}^{+}$ & $5.5 \pm 5.7$ & $7.5 \pm 8.1$ & $5.6 \pm 5.1$ & $8.1 \pm 8.5$ & $6.4 \pm 6.6$ & \\
$\mathrm{NO}_{3}^{-}$ & $128.2 \pm 36.1$ & $131.0 \pm 39.0$ & $127.8 \pm 38.3$ & $141.8 \pm 48.2$ & $141.9 \pm 41.9$ & \\
$\mathrm{H}_{2} \mathrm{O}_{2}$ & $109.1 \pm 34.8$ & $116.0 \pm 39.4$ & $132.0 \pm 43.1$ & $169.9 \pm 55.0$ & $92.1 \pm 32.7$ & \\
$\mathrm{Cond}$. & $1.6 \pm 0.5$ & $1.6 \pm 0.5$ & $1.6 \pm 0.5$ & $1.6 \pm 0.5$ & $1.7 \pm 0.5$ & \\
\hline Species & $\mathrm{F} 2$ & $\mathrm{~F} 3$ & NEEM-2008-S1 & $\mathrm{B} 26$ & $\mathrm{~B} 29$ & Kuramoto pit \\
\hline $\mathrm{Ca}^{2+}$ & - & $5.5 \pm 4.4$ & $7.4 \pm 5.4$ & $10.7 \pm 5.1$ & $17.4 \pm 8.9$ & $6.1 \pm 5.7$ \\
$\mathrm{Na}^{+}$ & - & $12.4 \pm 11.7$ & $12.9 \pm 11.9$ & $17.8 \pm 14.9$ & - & $11.2 \pm 10.9$ \\
$\mathrm{NH}_{4}^{+}$ & $8.7 \pm 11.9$ & $7.0 \pm 9.9$ & $7.5 \pm 4.3$ & $16.4 \pm 11.4$ & $7.0 \pm 3.9$ & - \\
$\mathrm{NO}_{3}^{-}$ & $153.8 \pm 50.0$ & $162.6 \pm 51.0$ & $146.1 \pm 32.3$ & $119.0 \pm 24.1$ & - & $138.4 \pm 55.3$ \\
$\mathrm{H}_{2} \mathrm{O}_{2}$ & $200.0 \pm 59.3$ & $192.1 \pm 50.1$ & $115.7 \pm 17.7$ & - & $143.5 \pm 31.1$ & - \\
$\mathrm{Cond}^{2}$ & $1.8 \pm 0.5$ & $2.1 \pm 0.6$ & $2.0 \pm 0.6$ & - & - & - \\
\hline
\end{tabular}


Table 4. Accumulation of the dice five cores in $\mathrm{m}$ w. eq.

\begin{tabular}{lcccc}
\hline Cores & Buizert density & SD & $\begin{array}{c}\text { Herron Langway } \\
\text { Density }\end{array}$ & SD \\
\hline M & 0.246 & 0.049 & 0.252 & 0.051 \\
$\mathrm{~N}$ & 0.252 & 0.048 & 0.259 & 0.049 \\
$\mathrm{E}$ & 0.259 & 0.077 & 0.265 & 0.077 \\
$\mathrm{~S}$ & 0.257 & 0.059 & 0.264 & 0.061 \\
$\mathrm{~W}$ & 0.244 & 0.053 & 0.250 & 0.055 \\
\hline Mean & 0.251 & 0.057 & 0.258 & 0.059 \\
\hline
\end{tabular}

explain more than $85 \%$ in all species. For the annual mean data, however, the representativeness of one core in $\mathrm{Na}^{+}$, $\mathrm{Ca}^{2+}$ and $\mathrm{H}_{2} \mathrm{O}_{2}$ is low, around $30 \%$, and higher for $\mathrm{NH}_{4}^{+}$, $\mathrm{NO}_{3}^{-}$and conductivity (around $60 \%$ ). For five cores the annual representativeness is never below $68 \%$.

The similarity of the representativeness values of concentrations and fluxes points to the fact that the annual accumulation plays a minor role in influencing the representativeness. Only for $\mathrm{Na}^{+}$and $\mathrm{H}_{2} \mathrm{O}_{2}$ do the fluxes appear to be more representative by about $20 \%$.

In Fig. 6 the single month representativeness is shown. The vertical bars show the $95 \%$ confidence intervals as retrieved by the bootstrap analysis. On the right-hand side, the representativeness of the annual data (see also Table 5) is shown again. If the inter-annual variability in means of individual months is considered (e.g. the inter-annual variability of all January values) then the representativeness values drops to values similar to those of annual mean values.

Note that we need to take into account the fact that $\tilde{R}_{n, N}^{2}$ is only an approximation. The quality of this approximation has been verified by comparing $\tilde{R}_{n, N}^{2}$ with $\bar{R}_{n, N}^{2}$ for $n=$ $(1, \ldots, 4)$ and $N=5$ (for $n=5, \tilde{R}_{5,5}^{2}=1$ for all species). The differences in the approximation and the real representativeness for $n=4$ range from 0.01 to $0.2 \%$ for the monthly time series and from 0.22 to $1.24 \%$ for the annual time series.

\subsection{Representativeness on different spatial scales}

In Fig. 8 the representativeness between two cores with similar distances is shown for monthly resolution which includes the seasonal variation (top) and annual resolution (bottom) on the different spatial scales (see Sect. 2.7). The representativeness of the dice five cores (long horizontal bars in Fig. 8) is subdivided according to the different distances within the dice five. The error bars depict the standard deviation of the representativeness of all subsets of two cores - e.g. for the side distance of the dice five we have four subsets: $(\mathrm{N}, \mathrm{E})$, $(\mathrm{N}, \mathrm{W}),(\mathrm{E}, \mathrm{S})$ and $(\mathrm{S}, \mathrm{W})$.

The representativeness for distances involving cores F2 and $\mathrm{F} 3$ cannot be shown for $\mathrm{Ca}^{2+}$ and $\mathrm{Na}^{+}$since the measurements were corrupted to some extent leaving not enough years to test for the representativeness. As there is only one subset (i.e. F2 and F3), it is not possible to calculate a standard deviation. To provide an estimate of uncertainty, the data have been bootstrapped. Standard deviations of the bootstrapped representativeness values are shown as vertical error bars. In Fig. 8 the mean of the bootstrapped representativeness values is shown in black. For the other species, representativeness values between cores F2, F3 and M, N, E, S, W and non-bootstrapped standard deviations are shown.

The representativeness values for the different distances within the dice five formation of the cores are of low statistical significance due to the low population size. Nevertheless, the representativeness generally slightly decreases in $\mathrm{Ca}^{2+}$, $\mathrm{Na}^{+}, \mathrm{NH}_{4}^{+}$and $\mathrm{H}_{2} \mathrm{O}_{2}$ for increasing distances. Considering only the mean values of the dice five formation, the representativeness of the longest distance is always the smallest. However, the overlap of the variability within the five cores and the values for long-distance representativeness point to the fact that the representativeness does not change much more between $10 \mathrm{~m}$ and $3 \mathrm{~km}$. On the other hand, for the step in distance from $0.6 \mathrm{~m}$ to larger distances, the largest decrease in representativeness values is observed.

The representativeness of annually resolved data results in very similar results, albeit the representativeness is considerably smaller in $\mathrm{Ca}^{2+}, \mathrm{Na}^{+}, \mathrm{H}_{2} \mathrm{O}_{2}$ and conductivity, and the standard deviations considerably larger due to the smaller amount of data points available (see Fig. 8 bottom).

\subsection{Modern seasonality}

Seasonality for pre-industrial and modern times are shown for both accumulation scenarios in Fig. 9, where scenario 1 refers to a constant accumulation rate throughout the year, while scenario 2 refers to twice the accumulation in summer than in winter.

Regarding modern seasonality and considering accumulation scenario $1, \mathrm{Ca}^{2+}$ peaks distinctively in March, shortly after $\mathrm{Na}^{+}$, which peaks in February. The $\mathrm{NO}_{3}^{-}$and $\mathrm{NH}_{4}^{+}$both peak in May. Whereas for other species seasonality does not change when computing the median instead of the mean, it is crucial to compute the median for $\mathrm{NH}_{4}^{+}$since there are many extremely high $\mathrm{NH}_{4}^{+}$peaks during summer, biasing the mean value. This is best seen in the shaded area depicting the mean absolute deviation, showing highest variability during late spring and summer followed by a sudden decline in September and almost no variability for the rest of the year. The $\mathrm{H}^{+}$measurements (not shown) show exactly the same seasonality as conductivity, which is an indicator of conductivity being driven mostly by $\mathrm{H}^{+}$.

Considering accumulation scenario 2, maxima of $\mathrm{Ca}^{2+}$ and $\mathrm{Na}^{+}$are generally broader than in scenario 1 , whereas maxima in $\mathrm{NO}_{3}^{-}, \mathrm{NH}_{4}^{+}$and $\mathrm{H}_{2} \mathrm{O}_{2}$ become narrower. Small temporal shifts in maxima are observed for $\mathrm{Ca}^{2+}$, which is shifted towards April, and $\mathrm{NO}_{3}^{-}$which is shifted towards June. Nevertheless, the use of different accumulation 
Table 5. Representativeness of the dice five data.

\begin{tabular}{lcccccc}
\hline & \multicolumn{2}{c}{$\begin{array}{c}\text { Monthly } \\
\text { resolution }\end{array}$} & \multicolumn{2}{c}{$\begin{array}{c}\text { Annual } \\
\text { resolution }\end{array}$} & \multicolumn{2}{c}{$\begin{array}{c}\text { Annual } \\
\text { flux }\end{array}$} \\
\hline Species & $\tilde{R}_{1, \infty}^{2}$ & $\tilde{R}_{5, \infty}^{2}$ & $\tilde{R}_{1, \infty}^{2}$ & $\tilde{R}_{5, \infty}^{2}$ & $\tilde{R}_{1, \infty}^{2}$ & $\tilde{R}_{5, \infty}^{2}$ \\
\hline $\mathrm{Ca}^{2+}$ & 0.73 & 0.93 & 0.35 & 0.73 & 0.37 & 0.75 \\
$\mathrm{Na}^{+}$ & 0.61 & 0.89 & 0.30 & 0.68 & 0.46 & 0.81 \\
$\mathrm{NH}_{4}^{+}$ & 0.65 & 0.90 & 0.73 & 0.93 & 0.78 & 0.95 \\
$\mathrm{NO}_{3}^{-}$ & 0.61 & 0.87 & 0.57 & 0.87 & 0.59 & 0.88 \\
$\mathrm{H}_{2} \mathrm{O}_{2}$ & 0.63 & 0.89 & 0.35 & 0.73 & 0.67 & 0.91 \\
$\mathrm{Cond}^{2}$ & 0.65 & 0.90 & 0.63 & 0.90 & 0.59 & 0.88 \\
\hline
\end{tabular}

scenarios has only a small influence on the derived seasonality in all components.

Daily samples of surface snow at Summit, Greenland from June 1997 to April 1998 and from August 2000 to August 2002 show high $\mathrm{Ca}^{2+}$ concentrations during April (Dibb et al., 2007). This is consistent with our data, assuming accumulation scenario 2 to be more realistic. For $\mathrm{NH}_{4}^{+}$, Dibb et al. (2007) found a broad mean summer enhancement from June to August. Considerably later than the maximum in our median values, $\mathrm{NH}_{4}^{+}$mean values exhibit a broad peak from June to August in both accumulation scenarios. The peak in the mean values from scenario 2 is much more distinct, and very similar to the measurements of Dibb et al. (2007). Also similar to Dibb et al. (2007), although less distinctive, $\mathrm{NO}_{3}^{-}$peaks in June in scenario 2. In addition to the summer peak, Dibb et al. (2007) find a distinctive peak in January. This peak cannot be seen distinctively in our mean seasonality data; however, the variability (shaded area in Fig. 9) shows an increase during December-January indicating that some of the years show a December-January peak. This is also supported by looking at the individual records in Fig. 7, which show a tendency to secondary peaks or shoulders during that time of the year.

Seasonalities of chemical tracers from Yalcin et al. (2006) for four snow pits at Eclipse ice field, Canada (dug during May and June 2002) with respect to $\delta^{18} \mathrm{O}$ agrees well with modern $\mathrm{Ca}^{2+}, \mathrm{NO}_{3}^{-}$and $\mathrm{NH}_{4}^{+}$concentrations in scenario 2, assuming the $\delta^{18} \mathrm{O}$ minimum to be in January. In contrast, $\mathrm{Na}^{+}$from Yalcin et al. (2006) leads with respect to our data by about two months, showing that there are regional differences in the sea salt aerosol supply to Arctic ice core sites.

\subsection{Pre-industrial seasonality}

The pre-industrial seasonality has been calculated on the NEEM-2008-S1 core using $\mathrm{Na}^{+}$as a time marker for February implying that the timing of $\mathrm{Na}^{+}$deposition has not changed over time. Interestingly, in contrast to modern seasonality, $\mathrm{Na}^{+}$peaks more distinctively during pre-industrial times. It shows similar concentrations except that during winter and early spring, the concentrations are about $5 \mathrm{ng} \mathrm{g}^{-1}$ higher.

Pre-industrial $\mathrm{Ca}^{2+}$ concentration peaked in March, similar to modern seasonality, but less distinct. Pre-industrial concentrations are generally higher in summer months, but lower in winter months compared to modern seasonality.

In contrast to the maximum in May during modern times, median $\mathrm{NH}_{4}^{+}$monthly values peaked in July-August during pre-industrial times. The pre-industrial seasonality is more symmetric than the modern one, which is skewed towards the beginning of the year for median monthly values. Looking at mean monthly values which are dominated by singular summer events, we note a shift from autumn towards summer from pre-industrial to modern times.

$\mathrm{NO}_{3}^{-}$shows its maximum in May and its minimum in September-October during modern times. During preindustrial times its maximum is substantially shifted to JuneJuly and its minimum to December-January. Generally, the pre-industrial $\mathrm{NO}_{3}^{-}$seasonality is more flat and in the order of $100 \mathrm{ng} \mathrm{g}^{-1}$ lower compared to modern seasonality.

At larger depths we observe that $\mathrm{H}_{2} \mathrm{O}_{2}$ follows the inverse concentration of dust and $\mathrm{Ca}^{2+}$. This is believed to be due to catalytic effects with $\mathrm{Mn}^{2+}$ or other heavy-metal ions (correlating with dust and $\mathrm{Ca}^{2+}$ ) which strengthens the decomposing of $\mathrm{H}_{2} \mathrm{O}_{2}$ into $\mathrm{H}_{2} \mathrm{O}$ and $\mathrm{O}_{2}$, as described in Weiss (1935). Since $\mathrm{H}_{2} \mathrm{O}_{2}$ is heavily affected by those effects, it does not represent its atmospheric seasonality.

Whitlow et al. (1992) showed maxima timing of $\mathrm{H}_{2} \mathrm{O}_{2}$, $\mathrm{NO}_{3}^{-}, \mathrm{NH}_{4}^{+}, \mathrm{Ca}^{2+}$ and $\mathrm{Na}^{+}$relative to $\delta^{18} \mathrm{O}$ from $\mathrm{AD} 1259$ to 1900 in Summit. Assuming the $\delta^{18} \mathrm{O}$ minimum to occur in January, all data agree within 1 month with our pre-industrial seasonalities.

\section{Discussion}

\subsection{Representativeness}

The representativeness of the monthly resolved dice five firn core data is always larger or equal to the representativeness of the annually resolved data, except for $\mathrm{NH}_{4}^{+}$which shows higher representativeness in the annually resolved data, if only one core is considered. The overall lower representativeness of the annual data is to be expected since most of the variance resides in the common seasonal cycle in each core.

In the particular case of $\mathrm{NH}_{4}^{+}$, the higher representativeness of the annual data comes from the singular summer peaks which dominate the variance in the annual data. From the high representativeness and the low confidence intervals in $\mathrm{NH}_{4}^{+}$during summer months we can also see that the common variance in the different cores is dominated by exceptionally large summer peaks in individual years.

Looking at the single month representativeness in Fig. 6 we note that $\mathrm{Ca}^{2+}$ and $\mathrm{Na}^{+}$show rather low 

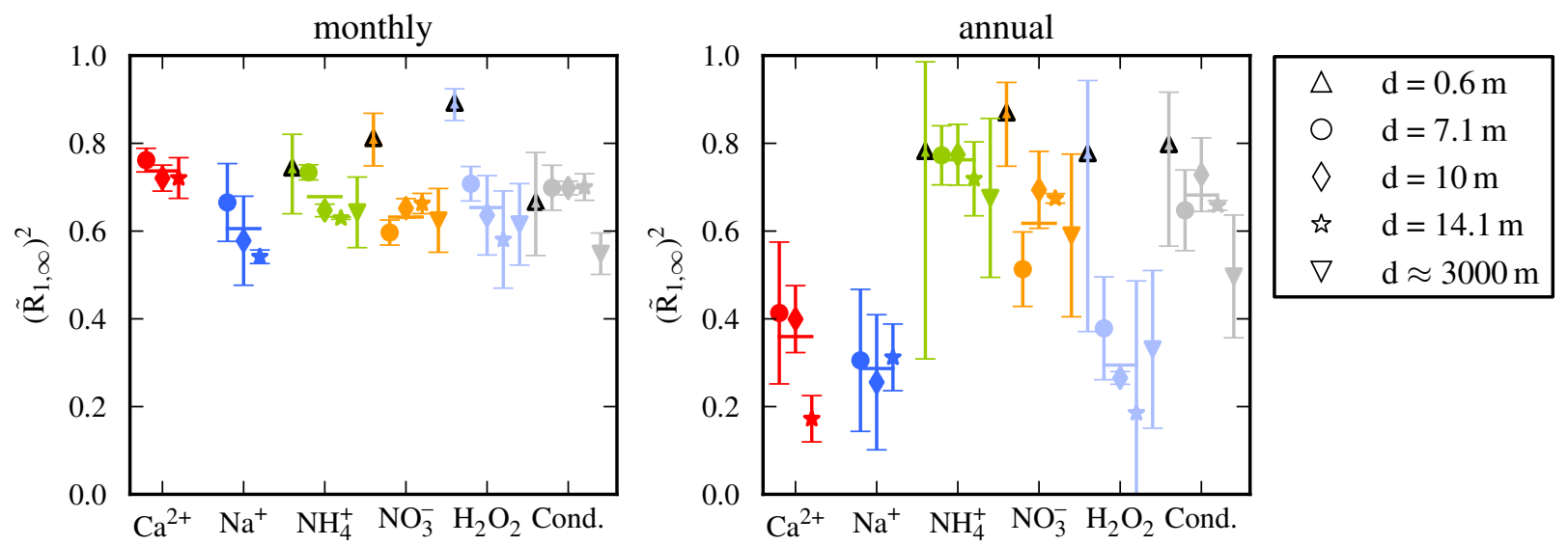

Figure 8. The $\tilde{R}_{1, \infty}^{2}$ values of the seasonal (left) and annual (right) variations, calculated for each two cores dependent on their distances ( $d=0.6 \mathrm{~m}$ : cores F2 and F3, $d=7.1 \mathrm{~m}, d=10 \mathrm{~m}$ and $d=14.1 \mathrm{~m}$ : dice five cores and $d=3000 \mathrm{~m}$ dice five cores and F2, F3). Horizontal bars represent $\tilde{R}_{1, \infty}^{2}$ of all subsets of two of the dice five cores. Variability in the $\tilde{R}_{1, \infty}^{2}$ estimates is given as the standard deviation. Black indicators show where the standard deviation is derived from bootstrapping the representativeness values.

representativeness values during the month with highest concentration. This could be due to the higher wind speeds during winter months. However, looking at the rather large confidence intervals, those results should not be over-interpreted. In contrast to those two species, $\mathrm{NO}_{3}^{-}$and $\mathrm{H}_{2} \mathrm{O}_{2}$ show highest single month representativeness during the months during which the seasonal concentration is highest. The high concentrations in $\mathrm{NO}_{3}^{-}$and $\mathrm{H}_{2} \mathrm{O}_{2}$ are therefore very robust. In addition to the lower wind speeds during the months of high $\mathrm{NO}_{3}^{-}$and $\mathrm{H}_{2} \mathrm{O}_{2}$ concentrations, one could speculate that a reason for the high representativeness could be the diffusion of $\mathrm{H}_{2} \mathrm{O}_{2}$ in the ice and the post-depositional loss of $\mathrm{NO}_{3}^{-}$, which might both be enhanced during warmer months.

Looking at species $\mathrm{NH}_{4}^{+}, \mathrm{NO}_{3}^{-}$and $\mathrm{H}_{2} \mathrm{O}_{2}$ in Fig. 8, we deduce that most of their spatial decorrelation takes place between $60 \mathrm{~cm}$ and about $7 \mathrm{~m}$ and then stays rather constant up to $3 \mathrm{~km}$. We attribute this to wind-blown sastrugis which have a lateral extent typically larger than $60 \mathrm{~cm}$, resulting in very good representativeness values on centimetre distances. The dice five formation then would cover more than just one sastrugi with wind redistribution occurring within the sastrugi field, resulting in considerably smaller representativeness. The fact that the representativeness does not change significantly between the dice five and the about $3 \mathrm{~km}$ distant cores F2 and F3 shows that small-scale wind-driven sastrugis are the driving noise mechanism and not larger-scale dune formation or bedrock topography induced variations in surface accumulation that act on kilometre scales. This also confirms that the atmospheric aerosol concentration does not change significantly on this spatial scale, as expected.

The values in Table 5 show that a large part of the atmospheric aerosol information is lost for the inter-annual variability if only one core is used. In contrast, seasonal cycles can be reliably reconstructed on only one single core.
Accordingly, the gain of representativeness, if having five cores instead of just one, is considerably larger in the annually resolved data than in the monthly resolved. It is therefore especially worthwhile to drill more than just one core if one is interested in more than the seasonality. A minimum requirement to use ice core chemistry data to reconstruct the atmospheric inter-annual variability is that the variance in the inter-annual data is dominated by the atmospheric signal and not by depositional noise. That implies that the representativeness $\bar{R}_{1, \infty}^{2}$ should be at least 0.5 . As illustrated in Table 5 this would only be the case for $\mathrm{NH}_{4}^{+}, \mathrm{NO}_{3}^{-}$and conductivity. For all other species replicate coring is required. A truly reliable reconstruction of the atmospheric inter-annual variability should, from our point of view, have a signal-to-noise ratio of at least $4: 1\left(\bar{R}_{1, \infty}^{2} \geq 0.8\right)$ which would require five or more replicate cores for most of the species. Note that such replicate coring has to take place on a spatial scale of about $10 \mathrm{~m}$ to efficiently quantify the depositional noise. Replicate coring on the lower than $1 \mathrm{~m}$ scale will lead to erroneously high representativeness which is not reflecting the atmospheric homogeneity but the homogeneity in the snow reworking within a single sastrugi. On the other hand, replicate coring on the $1 \mathrm{~km}$ scale does not provide much additional information compared to cores drilled within $10 \mathrm{~m}$ distance. This result has strong implications for the use of aerosol chemistry data to reconstruct for example the variability in atmospheric teleconnection patterns such as the North Atlantic Oscillation (NAO) or the El Niño Southern Oscillation (ENSO), which are dominated by multi-annual variability. Here, substantially better reconstructions can be achieved in the future, using replicate coring within several metres distance between individual cores. Note that the representativeness values in Table 5 are only applicable to climate 


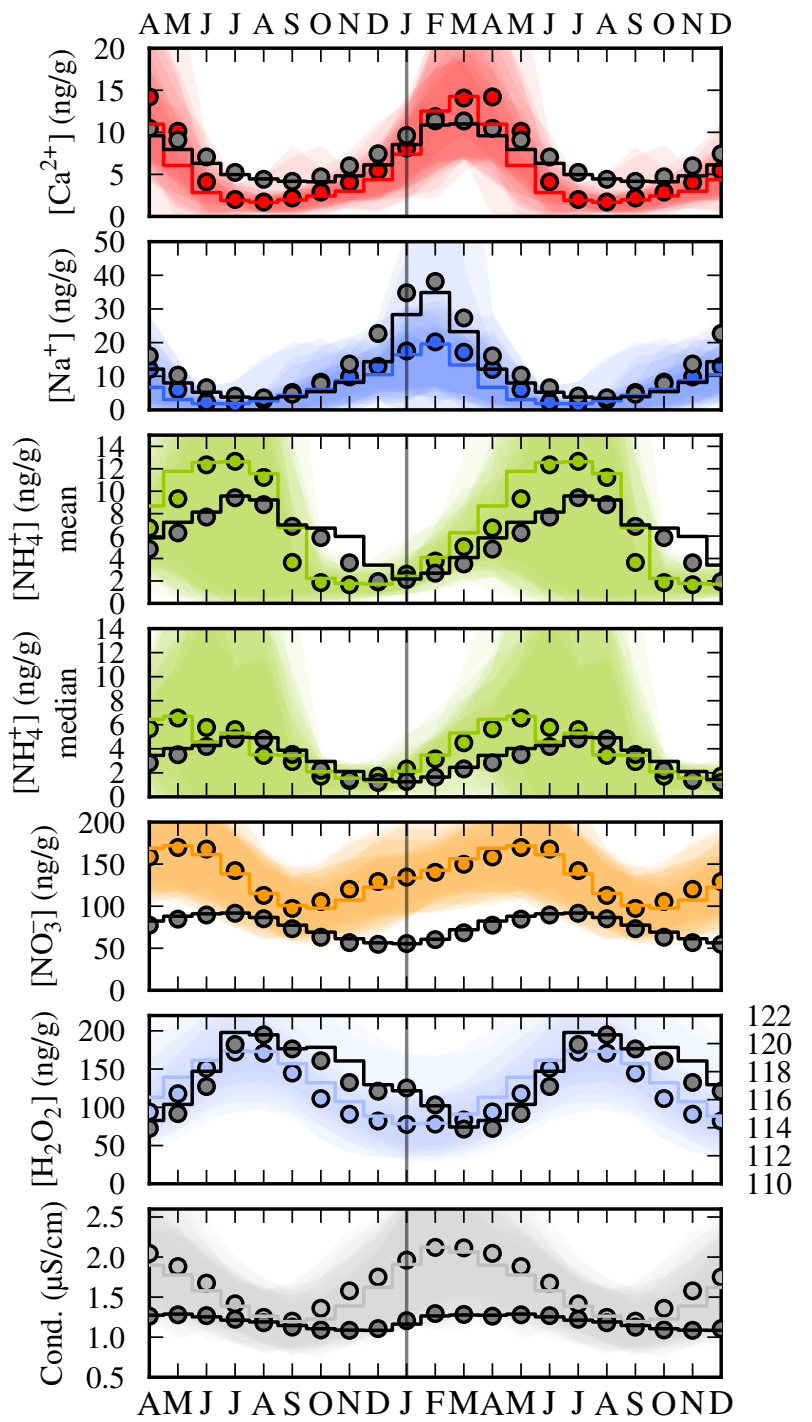

Figure 9. Average seasonality of the five firn cores (coloured stepplots). The average pre-industrial seasonality as derived from core S1 for the years AD 1623-1750 are shown as black step-plots. For $\mathrm{NH}_{4}^{+}$both median and mean values are shown. Line plots and scatter plots represent the accumulation scenarios 1 and 2, respectively. Shaded areas represent the variability of the seasonality of each of the dice five cores. Note that the pre-industrial values of $\mathrm{H}_{2} \mathrm{O}_{2}$ (right axis) do not represent atmospheric values (see text for more details).

conditions (mean annual accumulation, wind speed) at the NEEM site. Regions with higher accumulations and lower wind speeds are expected to provide higher representativeness values as the depositional noise due to sastrugi formation is expected to be relatively lower. Such regions would then be preferable for reconstruction of atmospheric teleconnection patterns and would require less replicate coring.

The representativeness of annual fluxes is only higher than that of concentrations for $\mathrm{Na}^{+}$and $\mathrm{H}_{2} \mathrm{O}_{2}$. This can be tentatively attributed to the predominantly wet deposition of these two aerosol species. As the variations in deposition fluxes of mainly wet-deposited aerosol species are controlled by both the inter-annual atmospheric aerosol concentration and the accumulation, a higher covariance is expected between different cores in the NEEM area when looking at flux values of these two species.

\subsection{Seasonality and anthropogenic influence}

The better agreement of the seasonality of the dice five firn cores from scenario 2 with the seasonality from snow pits and firn cores indicates that there is more accumulation during summer than during winter at NEEM. Nevertheless, we are not completely sure about the accumulation ratio between summer and winter.

The difference between pre-industrial and modern $\mathrm{Na}^{+}$ seasonality could be explained by either lower sea ice extent (if $\mathrm{Na}^{+}$originates from sea ice production as is suggested for Antarctica by Wolff et al., 2003) or wind speed changes for recent conditions, as wind speed is controlling the sea salt flux from the open ocean into the atmosphere. Similar to this explanation, the differences of pre-industrial and modern $\mathrm{Ca}^{2+}$ seasonality could be driven by changes in atmospheric circulations or by a change in storm frequency in the central Asian deserts where $\mathrm{Ca}^{2+}$ is mostly originating (Bory et al., 2003). However, the origin and transport of $\mathrm{Na}^{+}$and $\mathrm{Ca}^{2+}$ are still subjects of further investigation.

The high values of conductivity and $\mathrm{H}^{+}$in late winter and early spring are attributed to anthropogenic aerosol species and the well known Arctic haze phenomenon. The Arctic haze phenomenon arises due to the slow removal processes in the dry and stable Arctic atmosphere during winter (e.g. Law and Stohl, 2007; Shaw, 1995), which causes the anthropogenic pollution to build up. The most dominant anthropogenic acid in the Arctic atmosphere is $\mathrm{H}_{2} \mathrm{SO}_{4}$ due to $\mathrm{SO}_{2}$ emissions (Laj et al., 1992). Unfortunately we were not able to measure $\mathrm{SO}_{4}^{2-}$ with our CFA system - however, the high $\mathrm{H}_{2} \mathrm{SO}_{4}$ values are imprinted in high $\mathrm{H}^{+}$concentrations and due to the high molar conductivity of $\mathrm{H}^{+}$ $\left(349.8 \mathrm{~S} \mathrm{~cm}^{2} \mathrm{~mol}^{-1}\right)$ also in conductivity.

One of the additional constituents of the Arctic haze is $\mathrm{NO}_{3}^{-}$. As derived from several shallow firn cores during the North Greenland Traverse by Fischer et al. (1998b), anthropogenic maximum $\mathrm{NO}_{3}^{-}$firn concentration are 100 $130 \mathrm{ng} \mathrm{g}^{-1}$ higher than the pre-industrial background. Considering Fig. 9 we can confirm this finding also for the NEEM region. However, according to Fischer et al. (1998a), the recent $\mathrm{NO}_{3}^{-}$seasonality is only weakly defined in northeast Greenland with only slightly higher levels in summer and possibly spring. The reason for the lower variability is at least partly post-depositional $\mathrm{NO}_{3}^{-}$loss in this low accumulation region. While we can confirm the higher summer levels (only during early summer) in the NEEM region, we see a rather distinct seasonality with an amplitude of more 
than $50 \mathrm{ng} \mathrm{g}^{-1}$. Goto-Azuma and Koerner (2001) state that for some sites, two distinct $\mathrm{NO}_{3}^{-}$peaks are measured (anthropogenic winter to early spring peak and natural summer peak), whereas for other sites those two peaks are combined, forming one single peak. The combination of the two peaks could be an explanation for the rather early summer peak in the modern $\mathrm{NO}_{3}^{-}$seasonality derived from the dice five cores. However, considering the pre-industrial seasonality to be $100 \mathrm{ng} \mathrm{g}^{-1}$ lower and overall flatter than the modern seasonality, we can say that a natural summer peak is completely obscured in the modern seasonality at NEEM.

Langford et al. (1992) state that the fixation of the ubiquitous product of biological activities ammonia $\left(\mathrm{NH}_{3}\right)$ in the atmosphere happens primarily through irreversible processes with $\mathrm{H}_{2} \mathrm{SO}_{4}$ to form $\mathrm{NH}_{4} \mathrm{HSO}_{4}$ and $\left(\mathrm{NH}_{4}\right)_{2} \mathrm{SO}_{4}$. This could explain the increase in $\mathrm{NH}_{4}^{+}$concentration in February to April for recent conditions, when biological activity is still low. Due to the phenomenon of the Arctic haze a lot of $\mathrm{H}_{2} \mathrm{SO}_{4}$ is present during this time which could turn even a small amount of ammonia into $\mathrm{NH}_{4}^{+}-$an effect that was certainly not that strong during pre-industrial times, except during times of volcanic eruptions. In addition, enhanced anthropogenic $\mathrm{NH}_{3}$ emissions during spring preferentially from farming may contribute to the recent spring maximum in $\mathrm{NH}_{4}^{+}$. In contrast, the later $\mathrm{NH}_{4}^{+}$maximum for pre-industrial conditions is most likely controlled by high biological productivity during summer.

Alternatively it is imaginable that the assumptions on scenario 2 might only to some extent reflect the reality. A larger summer-winter accumulation ratio than $2: 1$ would stretch the winter signal even more, shifting the increase of $\mathrm{NH}_{4}^{+}$towards the seasonality of biological activity. A higher summer-winter accumulation ratio would also shift the preindustrial and modern mean seasonality closer together however, that would also affect the seasonality of all the other species.

\subsection{Trends}

Core NEEM-2008-S1 shows an increasing trend in the annual data in $\mathrm{NO}_{3}^{-}$and conductivity since the late 19th century (see Fig. 3) corresponding to the beginning of the industrial revolution. Since the mid-1970s $\mathrm{NO}_{3}^{-}$flattens out whereas conductivity even decreases. In the other species such as $\mathrm{Ca}^{2+}, \mathrm{Na}^{+}$and $\mathrm{NH}_{4}^{+}$, core NEEM-2008-S1 does not show any significant increase over the industrial period. The species analysed in the dice five firn cores do not show any significant trend in the annual means over the short time period covered, but some components show significant trends in some monthly values. $\mathrm{H}^{+}$and conductivity show similar significant decreases in winter months with $r$ generally lower than 0.5, continuing the decrease observed in core NEEM2008-S1. The decrease in $\mathrm{H}^{+}$in winter months is also confirmed by air measurements at Alert station which show significant negative trends between November and April with $r$ between -0.48 and -0.81 over the time period from 1980 to 2003. The $\mathrm{SO}_{4}^{2-}$ measurements at Alert station show similar results, with negative trends for November, June and September with $r$ between -0.45 and -0.83 . Accordingly, the decreasing trend in $\mathrm{H}^{+}$most likely reflects the reduced anthropogenic $\mathrm{SO}_{4}^{2-}$ aerosol load in the Arctic as evidenced in many deeper ice core studies in Greenland (e.g. Fischer et al., 1998b; Bigler et al., 2002). In addition, this is supported by the decrease of sulfur dioxide $\left(\mathrm{SO}_{2}\right)$ emissions since the mid1970s as described by Smith et al. (2011), and supported by Law and Stohl (2007) who state $\mathrm{SO}_{4}^{2-}$ to exhibit significant downward trends at most Arctic stations.

\section{Conclusions}

The firn cores and the snow pit analysed in this work agree well with data available in the literature from other firn cores and snow pits.

The seasonalities derived from different firn cores agree very well with each other enabling us to give accurate maxima and minima timings in monthly resolution. Comparison with Dibb et al. (2007) showed that accumulation scenario 2 (summer accumulation of two times the winter accumulation) is more likely than scenario 1 (same accumulation throughout the year) although it is possible that even a larger summer to winter accumulation ratio than $2: 1$ might be more adequate.

One of the main goals of this study was to investigate how representative aerosol chemistry records in the NEEM region are in terms of atmospheric concentration variability and how strongly the depositional noise affects ice core variations.

A single core is representative of more than $60 \%$ of variability within a square with $10 \mathrm{~m}$ side length in all species in terms of seasonal cycles (monthly resolution), thus counting of annual layers using seasonal cycles in chemistry records can be reliably achieved using a single ice core at NEEM. Considering annually resolved data, the representativeness drops significantly in $\mathrm{Ca}^{2+}, \mathrm{Na}^{+}, \mathrm{H}_{2} \mathrm{O}_{2}$ and $\mathrm{H}^{+}$whereas it remains high in $\mathrm{NH}_{4}^{+}, \mathrm{NO}_{3}^{-}$and conductivity.

Accordingly, the inter-annual variability in atmospheric aerosol concentrations (for example linked to variations in atmospheric teleconnection patterns) cannot be reliably reconstructed from a single ice core at NEEM. Replicate coring of ice cores within several metres distance, however, can provide ice core records reliable for inter-annual variability in this region. Therefore, replicate coring is highly desirable for reconstructions of teleconnection patterns in future studies. We suggest that a reliable reconstruction of the inter-annual variability in aerosol concentrations at NEEM requires at least five replicate cores. This number is most likely smaller (higher) in higher (lower) accumulation areas on the Greenland ice sheet.

The representativeness of cores only several tens of centimetres apart is higher than for cores that are drilled within 
a few metres distance. The representativeness does not diminish further if the firn cores are compared with a distance of a few kilometres. This implies that most likely sastrugis can explain the depositional noise. The higher representativeness of cores within a few tens of centimetre thus only reflects the common signal within one sastrugi, but not a higher representativeness for atmospheric variability.

Acknowledgements. NEEM is directed and organised by the Centre of Ice and Climate at the Niels Bohr Institute and US NSF, Office of Polar Programs. It is supported by funding agencies and institutions in Belgium (FNRS-CFB and FWO), Canada (NRCan/GSC), China (CAS), Denmark (FIST), France (IPEV, CNRS/INSU, CEA and ANR), Germany (AWI), Iceland (RannIs), Japan (NIPR), Korea (KOPRI), the Netherlands (NWO/ALW), Sweden (VR), Switzerland (SNF), UK (NERC) and the USA (US NSF, Office of Polar Programs). We thank the Swiss National Science Foundation (SNSF) for financial support and the four anonymous reviewers for improving the paper with their constructive comments. All figures were generated using the matplotlib library in the Python programming language.

Edited by: F. Dominé

\section{References}

Bigler, M., Wagenbach, D., Fischer, H., Kipfstuhl, J., Miller, H., Sommer, S., and Stauffer, B.: Sulphate record from a northeast Greenland ice core over the last 1200 years based on continuous flow analysis, Ann. Glaciol., 35, 250-256, doi:10.3189/172756402781817158, 2002.

Bory, A. J.-M., Biscaye, P. E., and Grousset, F. E.: Two distinct seasonal Asian source regions for mineral dust deposited in Greenland (NorthGRIP), Geophys. Res. Lett., 30, 1176, doi:10.1029/2002GL016446, 2003.

Buizert, C., Martinerie, P., Petrenko, V. V., Severinghaus, J. P., Trudinger, C. M., Witrant, E., Rosen, J. L., Orsi, A. J., Rubino, M., Etheridge, D. M., Steele, L. P., Hogan, C., Laube, J. C., Sturges, W. T., Levchenko, V. A., Smith, A. M., Levin, I., Conway, T. J., Dlugokencky, E. J., Lang, P. M., Kawamura, K., Jenk, T. M., White, J. W. C., Sowers, T., Schwander, J., and Blunier, T.: Gas transport in firn: multiple-tracer characterisation and model intercomparison for NEEM, Northern Greenland, Atmos. Chem. Phys., 12, 4259-4277, doi:10.5194/acp-12-4259-2012, 2012.

Cleveland, W. S.: Robust Locally Weighted Regression and Smoothing Scatterplots, J. Am Stat. Assoc., 74, 829-836, 1979.

Dahl-Jensen, D., Albert, M., Aldahan, A., Azuma, N., BalslevClausen, D., Baumgartner, M., Berggren, A.-M., Bigler, M., Binder, T., Blunier, T., Bourgeois, J., Brook, E., Buchardt, S., Buizert, C., Capron, E., Chappellaz, J., Chung, J., Clausen, H., Cvijanovic, I., Davies, S. M., Ditlevsen, P., Eicher, O., Fischer, H., Fisher, D., Fleet, L., Gfeller, G., Gkinis, V., Gogineni, S., Goto-Azuma, K., Grinsted, A., Gudlaugsdottir, H., Guillevic, M., Hansen, S., Hansson, M., Hirabayashi, M., Hong, S., Hur, S., Huybrechts, P., Hvidberg, C., Iizuka, Y., Jenk, T., Johnsen, S., Jones, T., Jouzel, J., Karlsson, N., Kawamura, K., Keegan, K., Kettner, E., Kipfstuhl, S., Kjær, H., Koutnik, M., Kuramoto,
T., Köhler, P., Laepple, T., Landais, A., Langen, P., Larsen, L., Leuenberger, D., Leuenberger, M., Leuschen, C., Li, J., Lipenkov, V., Martinerie, P., Maselli, O., Masson-Delmotte, V., McConnell, J., Miller, H., Mini, O., Miyamoto, A., MontagnatRentier, M., Mulvaney, R., Muscheler, R., Orsi, A., Paden, J., Panton, C., Pattyn, F., Petit, J.-R., Pol, K., Popp, T., Possnert, G., Prié, F., Prokopiou, M., Quiquet, A., Rasmussen, S., Raynaud, D., Ren, J., Reutenauer, C., Ritz, C., Röckmann, T., Rosen, J., Rubino, M., Rybak, O., Samyn, D., Sapart, C., Schilt, A., Schmidt, A., Schwander, J., Schüpbach, S., Seierstad, I., Severinghaus, J., Sheldon, S., Simonsen, S., Sjolte, J., Solgaard, A., Sowers, T., Sperlich, P., Steen-Larsen, H., Steffen, K., Steffensen, J., Steinhage, D., Stocker, T., Stowasser, C., Sturevik, A., Sturges, W., Sveinbjörnsdottir, A., Svensson, A., Tison, J.L., Uetake, J., Vallelonga, P., van de Wal, R., van der Wel, G., Vaughn, B., Vinther, B., Waddington, E., Wegner, A., Weikusat, I., White, J., Wilhelms, F., Winstrup, M., Witrant, E., Wolff, E., Xiao, C., and Zheng, J.: Eemian interglacial reconstructed from a Greenland folded ice core, Nature, 493, 489-494, 2013.

Dibb, J. E., Whitlow, S. I., and Arsenault, M.: Seasonal variations in the soluble ion content of snow at Summit. Greenland: constraints from three years of daily surface snow samples, Atmos. Environ., 41, 5007-5019, recent Investigations of Snow Photochemistry and Air-Snow Exchange at Summit, Greenland, 2007.

Dunse, T., Eisen, O., Helm, V., Rack, W., Steinhage, D., and Parry, V.: Characteristics and small-scale variability of GPR signals and their relation to snow accumulation in Greenland's percolation zone, J. Glaciol., 54, 333-342, doi:10.3189/002214308784886207, 2008.

Fischer, H.: Räumliche Variabilität in Eiskernzeitreihen Nordostgrönlands, Ph.D. thesis, Ruprecht-Karls-Universität Heidelberg, 1997.

Fischer, H., Wagenbach, D., and Kipfstuhl, J.: Sulfate and nitrate firn concentrations on the Greenland ice sheet: 1. Large-scale geographical deposition changes, J. Geophys. Res.-Atmos., 103, 21927-21934, doi:10.1029/98JD01885, 1998a.

Fischer, H., Wagenbach, D., and Kipfstuhl, J.: Sulfate and nitrate firn concentrations on the Greenland ice sheet: 2. Temporal anthropogenic deposition changes, J. Geophys. Res.-Atmos., 103, 21935-21942, doi:10.1029/98JD01886, 1998b.

Fischer, H., Siggaard-Andersen, M.-L., Ruth, U., Röthlisberger, R., and Wolff, E.: Glacial/interglacial changes in mineral dust and sea-salt records in polar ice cores: Sources, transport, and deposition, Rev. Geophys., 45, RG1002, doi:10.1029/2005RG000192, 2007.

Fisher, D., Reeh, N., and Clausen, H.: Stratigraphic noise in time series derived from ice cores, Ann. Glaciol., 7, 76-83, 1985.

Gfeller, G.: Continuous acidity measurements on polar ice cores, Master's thesis, University of Bern, Switzerland, 2011.

Goto-Azuma, K. and Koerner, R. M.: Ice core studies of anthropogenic sulfate and nitrate trends in the Arctic, J. Geophys. Res.Atmos., 106, 4959-4969, doi:10.1029/2000JD900635, 2001.

Hausbrand, R.: Direct measurement of the acidity in an ice core from northwest Greenland, Master's thesis, Ruprecht-KarlsUniversität Heidelberg, 1998.

Herron, M. M. and Langway, C. C.: Firn densification: an empirical model, J. Glaciol., 25, 373-385, 1980. 
Karlöf, L., Winebrenner, D. P., and Percival, D. B.: How representative is a time series derived from a firn core? A study at a low-accumulation site on the Antarctic plateau, Journal of Geophysical Research: Earth Surface, 111, F04001, doi:10.1029/2006JF000552, 2006.

Kaufmann, P. R., Federer, U., Hutterli, M. A., Bigler, M., Schüpbach, S., Ruth, U., Schmitt, J., and Stocker, T. F.: An improved Continuous Flow Analysis system for high-resolution field Measurements on ice cores, Environ. Sci. Technol., 42, 8044-8050, doi:10.1021/es8007722, 2008.

Kuramoto, T., Goto-Azuma, K., Hirabayashi, M., Miyake, T., Motoyama, H., Dahl-Jensen, D., and Steffensen, J. P.: Seasonal variations of snow chemistry at NEEM, Greenland, Ann. Glaciol., 52, 193-200, doi:10.3189/172756411797252365, 2011.

Laj, P., Palais, J. M., and Sigurdsson, H.: Changing sources of impurities to the Greenland ice sheet over the last 250 years, Atmos. Environ., 26, 2627 - 2640, 1992.

Langford, A. O., Fehsenfeld, F. C., Zachariassen, J., and Schimel, D. S.: Gaseous ammonia fluxes and background concentrations in terrestrial ecosystems of the United States, Global Biogeochem. Cy., 6, 459-483, doi:10.1029/92GB02123, 1992.

Law, K. S. and Stohl, A.: Arctic air pollution: origins and impacts, Science, 315, 1537-1540, doi:10.1126/science.1137695, 2007.

Legrand, M. and Mayewski, P.: Glaciochemistry of polar ice cores: a review, Rev. Geophys., 35, 219-243, doi:10.1029/96RG03527, 1997.

Mosley-Thompson, E., McConnell, J. R., Bales, R. C., Li, Z., Lin, P.-N., Steffen, K., Thompson, L. G., Edwards, R., and Bathke, D.: Local to regional-scale variability of annual net accumulation on the Greenland ice sheet from PARCA cores, J. Geophys. Res.Atmos., 106, 33839-33851, doi:10.1029/2001JD900067, 2001.

Röthlisberger, R., Bigler, M., Hutterli, M., Sommer, S., Stauffer, B., Junghans, H. B., and Wagenbach, D.: Technique for continuous high-resolution snalysis of trace substances in firn and ice cores, Environ. Sci. Technol., 34, 338-342, doi:10.1021/es9907055, 2000 .

Shaw, G. E.: The arctic haze phenomenon, Bulletin of the American Meteorological Society, 76, 2403-2413, doi:10.1175/15200477(1995)076<2403:TAHP>2.0.CO;2, 1995.

Sigg, A., Fuhrer, K., Anklin, M., Staffelbach, T., and Zurmuhle, D.: A continuous analysis technique for trace species in ice cores, Environ. Sci. Technol., 28, 204-209, doi:10.1021/es00051a004, 1994.
Smith, S. J., van Aardenne, J., Klimont, Z., Andres, R. J., Volke, A., and Delgado Arias, S.: Anthropogenic sulfur dioxide emissions: 1850-2005, Atmos. Chem. Phys., 11, 1101-1116, doi:10.5194/acp-11-1101-2011, 2011.

Sommer, S.: Hochauflösende spurenstoffuntersuchung an eisbohrkernen aus Nord-Grönland, Master's thesis, University of Bern, 1996.

Steen-Larsen, H. C., Masson-Delmotte, V., Sjolte, J., Johnsen, S. J., Vinther, B. M., Bréon, F.-M., Clausen, H. B., Dahl-Jensen, D., Falourd, S., Fettweis, X., Gallée, H., Jouzel, J., Kageyama, M., Lerche, H., Minster, B., Picard, G., Punge, H. J., Risi, C., Salas, D., Schwander, J., Steffen, K., Sveinbjörnsdottir, A. E., Svensson, A., and White, J.: Understanding the climatic signal in the water stable isotope records from the NEEM shallow firn/ice cores in Northwest Greenland, J. Geophys. Res.-Atmos., 116, D06108, doi:10.1029/2010JD014311, 2011.

Steffen, K., Box, J. E., and Abdalati, W.: Greenland Climate Network: GC-Net, Colbeck, S. C. Ed. CRREL 96-27 Special Report on Glaciers, Ice Sheets and Volcanoes, trib. to M. Meier, 98-103, 1996.

Weiss, J.: The catalytic decomposition of hydrogen peroxide on different metals, Trans. Faraday Soc., 31, 1547-1557, doi:10.1039/TF9353101547, 1935.

Whitlow, S., Mayewski, P. A., and Dibb, J. E.: A comparison of major chemical species seasonal concentration and accumulation at the South Pole and Summit, Greenland, Atmos. Environ., 26A, 2045-2054, 1992.

Wigley, T. M. L., Briffa, K. R., and Jones, P. D.: On the average value of correlated time series, with applications in dendroclimatology and hydrometeorology, J. Climate Appl. Meteorol., 23, 201-213, doi:10.1175/15200450(1984)023<0201:OTAVOC>2.0.CO;2, 1984.

Wolff, E. W., Rankin, A. M., and Röthlisberger, R.: An ice core indicator of Antarctic sea ice production?, Geophys. Res. Lett., 30, 2158, doi:10.1029/2003GL018454, 2003.

Yalcin, K., Wake, C. P., Kang, S., Kreutz, K. J., and Whitlow, S. I.: Seasonal and spatial variability in snow chemistry at Eclipse Icefield, Yukon, Canada, Ann. Glaciol., 43, 230-238, doi:10.3189/172756406781811998, 2006. 